\title{
Gut Microbiota and Dysbiosis in Alzheimer's Disease: Implications for Pathogenesis and Treatment
}

\author{
Shan Liu ${ }^{1} \cdot$ Jiguo Gao ${ }^{1} \cdot$ Mingqin Zhu ${ }^{1,2} \cdot$ Kangding Liu ${ }^{1} \cdot$ Hong-Liang Zhang ${ }^{3}$ (D)
}

Received: 18 May 2020 / Accepted: 11 August 2020 / Published online: 23 August 2020

(C) The Author(s) 2020

\begin{abstract}
Understanding how gut flora influences gut-brain communications has been the subject of significant research over the past decade. The broadening of the term "microbiota-gut-brain axis" from "gut-brain axis" underscores a bidirectional communication system between the gut and the brain. The microbiota-gut-brain axis involves metabolic, endocrine, neural, and immune pathways which are crucial for the maintenance of brain homeostasis. Alterations in the composition of gut microbiota are associated with multiple neuropsychiatric disorders. Although a causal relationship between gut dysbiosis and neural dysfunction remains elusive, emerging evidence indicates that gut dysbiosis may promote amyloid-beta aggregation, neuroinflammation, oxidative stress, and insulin resistance in the pathogenesis of Alzheimer's disease (AD). Illustration of the mechanisms underlying the regulation by gut microbiota may pave the way for developing novel therapeutic strategies for $\mathrm{AD}$. In this narrative review, we provide an overview of gut microbiota and their dysregulation in the pathogenesis of AD. Novel insights into the modification of gut microbiota composition as a preventive or therapeutic approach for $\mathrm{AD}$ are highlighted.
\end{abstract}

Keywords Alzheimer's disease · Gut microbiota $\cdot$ Microbiota-gut-brain axis · Gut dysbiosis

\section{Introduction}

Alzheimer's disease $(\mathrm{AD})$ is a progressive neurodegenerative disorder of the central nervous system (CNS) characteristic of gradual cognitive decline [1]. The presence of extracellular amyloid-beta $(\mathrm{A} \beta)$ deposition as neuritic plaques and intracellular accumulation of hyperphosphorylated tau as neurofibrillary tangles (NFTs) remain the primary neuropathological criteria for $\mathrm{AD}$ diagnosis [1]. As the most prevalent form of dementia, $\mathrm{AD}$ has emerged as a global public health priority affecting an estimated total of 50 million people worldwide [2]. The consistently growing prevalence and the heavy burden of $\mathrm{AD}$ render it more urgent than ever for researchers to

Kangding Liu

kangdingliu@163.com

Hong-Liang Zhang

drzhl@hotmail.com; zhanghl@nsfc.gov.cn

1 Department of Neurology, First Hospital of Jilin University, Jilin University, Xinmin Street 71, Changchun 130021, China

2 Departments of Laboratory Medicine and Pathology, Neurology and Immunology, Mayo Clinic, Rochester, MN, USA

3 Department of Life Sciences, National Natural Science Foundation of China, Shuangqing Road 83, Beijing 100085, China dissect the mechanisms underlying the pathogenesis of $\mathrm{AD}$ and to seek disease-modifying therapies (Fig. 1).

Since it was first proposed by Hardy and Higgins in 1992, the amyloid cascade hypothesis has been the dominant theory of $\mathrm{AD}$ pathogenesis which holds that the accumulation of $\mathrm{A} \beta$ peptides derived from amyloid precursor protein (APP) is the initial event of $\mathrm{AD}$ pathogenesis [3]. Over the ensuing decades, this hypothesis has evolved from a neuron-centric linear cascade, which postulates that $A \beta$ results in hyperphosphorylated tau and neurodegeneration, to an integrative model that also involves feedback and feedforward responses of impaired vasculature, oxidative stress (OS), microgliosis, and dysregulation of neuronal proteolysis [4, 5]. Extensive research suggests that aggregated, hyperphosphorylated forms of tau may also lead to synaptic communication disturbance as well as neuronal death [6]. Although candidate drugs that affect the formation, aggregation, and clearance of $A \beta$ and tau have yielded encouraging results in some preclinical trials, none have progressed to the clinical stage $[2,7]$.

Mounting evidence suggests that neuroinflammation is not just a consequence but a vital contributor to the development and progression of $\mathrm{AD}$. As such, the "inflammation hypothesis" is emerging as a surrogate mechanism of AD (Fig. 1). In this scenario, synaptic impairment and neuronal death are at 
Fig. 1 Key factors in the pathogenesis of $\mathrm{AD}$. amyloid plaques and intracellular NFTs, neuroinflammation, mitochondrial dysfunction, OS, IR, and chronic cerebral hypoperfusion are the main causes of AD development. These factors are related to each other directly or indirectly. Cerebral hypoperfusion due to advanced atherosclerosis or endothelial dysfunction, IR, and mitochondrial dysfunction lead to an elevation in ROS levels which results in overexpression and increased processing of APP, hyperphosphorylation of tau, and NFT pathology leading to neuronal death. $\mathrm{A} \beta$, TBI, and infections are some of the factors that can elicit inflammation. Abbreviations: $A \beta$ amyloid-beta, $A D$ Alzheimer's disease, $A P P$ amyloid precursor protein, $I R$ insulin resistance, $N F T$ neurofibrillary tangle, $O S$ oxidative stress, $R O S$ reactive oxygen species, $T B I$ traumatic brain injury

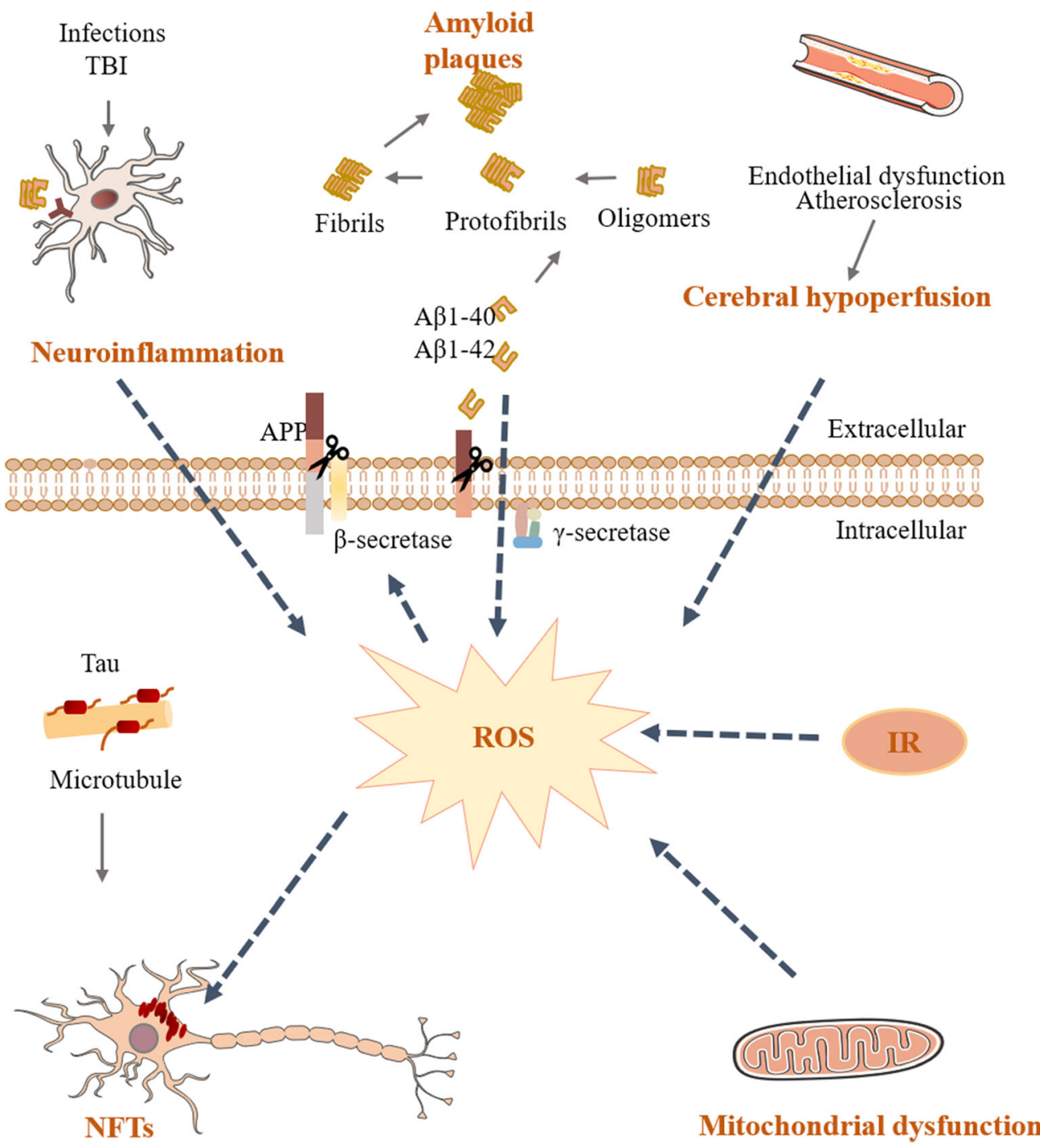

least partially mediated by excessive or non-resolving innate immune activation [8]. Extrinsic factors like infections and traumatic brain injury (TBI) can possibly interfere with the central immune homeostasis and accelerate disease progression $[9,10]$. The "inflammation hypothesis" was fueled by the discovery of inflammation susceptibility genes (e.g., CD33, TREM2) for AD through large-scale genome-wide association studies $[11,12]$.

Extensive research argues mitochondrial dysfunction [13], insulin resistance (IR) [14], and cerebral hypoperfusion [15] may mediate, drive, or possibly even initiate pathologic molecular cascades in $\mathrm{AD}$ and finally promote $\mathrm{A} \beta$ accumulation, tau hyperphosphorylation, synaptic degeneration, and neuronal dysfunction. However, current hypotheses in this regard are unable to satisfactorily explain the etiology and underlying pathophysiological mechanisms of AD. In recent years, the microbiota-gut-brain axis has emerged as a focal point of biomedical research and a potential therapeutic target for the treatment of CNS disorders $[16,17]$. In particular, dysfunction of the microbiota-gut-brain axis has been implicated in the pathogenesis of AD [19]. In this review, we will summarize the knowledge on the characteristics of the gut microbiota and the communication pathways of the microbiota-gut-brain axis, analyze the role of dysbiosis of the gut microbiota in the pathogenesis of $\mathrm{AD}$, and highlight the modification of gut microbiota composition as a preventive or therapeutic approach for AD.

\section{Human Gut Microbiota}

The human gut is an anaerobic bioreactor with a diverse population of microorganisms, including bacteria, yeast, archaea, viruses, protozoa, and parasites such as helminths, collectively known as microbiota, which occupy different niches of the mucosal surfaces in the gastrointestinal (GI) tract $[16,20]$. The application of DNA sequencing and metagenomic and metabolomic analysis technologies has reshaped our view of 
human gut flora and provided new insights into the characterization of microbiota and its intricate interplay with human health [18]. The microorganisms residing in the gut make up the vast majority of the human microbial population, including at least 1000 different bacterial species and approximately 150 times as many genes as in the human genome [21, 22]. The distinct microenvironment of each gut compartment selects the growth of specific microbiota, with the distal gut being the predominant habitat of the gut microbial community [22]. Firmicutes and Bacteroidetes constitute the most abundant phyla in human intestinal microbiota [23]. Initial colonization of the GI tract by gut microbiota is thought to commence at birth when the infant becomes exposed to maternal microbiota and other environmental factors during birth [24]. Importantly, the gut microbiota of vaginally born infants closely resembles the microbial compositions of the mothers' vagina, while newborns delivered via cesarean section are enriched with microbes found on human skin and in the surrounding environment [25]. Gut microbiota composition exhibits a large interindividual variability and heterogeneity that may be explained by an influence of both extrinsic, e.g., diet, antibiotics, lifestyle, and disease, and intrinsic factors, e.g., genetics $[26,27]$. The diverse commensal microbiota undergoes dynamic changes throughout life, as is evidenced by the fact that the number of species and the richness of gut microbiota composition decline prominently with age [28]. Intestinal microbiota is proposed as an essential "organ" which imparts substantial physiological functions related to innate immunity, appetite, and energy metabolism locally and systematically $[16,29]$. Abnormal changes in the composition of gut flora, a phenomenon known as dysbiosis, is also directly involved in the pathophysiology of diseases affecting several distant organs [30]. Gut dysbiosis may be associated with pathologies such as asthma [31], cardiovascular disease [32], type 2 diabetes mellitus (T2DM) [33], renal failure [34], and sarcopenia [35].

\section{The Microbiota-Gut-Brain Axis in Health and Disease}

The term "microbiota-gut-brain axis" broadened from "gutbrain axis" indicates the significant role of gut microbiota in modulating brain function. Albeit nascent in terms of the delineation of the mode of communication between gut microbiota and the brain, research using germ-free (GF) mice, antibiotic treatments, and prebiotic/probiotic complementation has provided persuasive evidence for several major potential pathways underlying the two-way communications between the GI tract and the CNS. At least five separate lines of evidence converged to support the hypothesis that gut microbiota can effectively communicate with the brain. First, it has long been known that a clinical situation, i.e., hepatic encephalopathy, is associated with gut dysbiosis and can be broadly treated by targeting the microbiota with antibiotics in humans; second, studies in GF animals showed that the brain function is affected by the absence of microbiota; third, lowlevel infections alter the behaviors of animals and humans even in the absence of immune activation; fourth, specific strains of exogenous bacteria alter the behaviors of animals and humans; and finally, antibiotic administration has longlasting effects on the nervous system [16, 17]. In this section, we will summarize the updated knowledge on role of the microbiota-gut-brain axis in health and disease from the perspective of metabolites, endocrine regulation (the hypothalamic-pituitary-adrenal [HPA] axis), neural transmission, and immunomodulation (Fig. 2) [16, 17].

\section{Metabolites}

The ability of bacteria to produce bioactive products provides a mechanistic basis to understand the role of gut microbiota in modulating central physiological and pathological processes [36]. Moreover, the emerging notion that the interplay between bacterial products and the brain can modulate behavior is intriguing. Different bacterial genera and species produce gamma-amino butyric acid (GABA), serotonin (5-HT), histamine, and dopamine (Table 1), which are all involved in a range of mood-related, behavioral, and cognitive functions as neurotransmitters or neurotransmitter precursors [43, 44]. During metabolism, the host and its gut microbiota coproduce a spectrum of metabolites, such as short-chain fatty acids (SCFAs), that are essential for host health [45]. SCFAs, which mainly consist of acetate, propionate, and butyrate, function through either $\mathrm{G}$ protein coupled receptors or histone deacetylases [46, 47]. Such microbial products are active mediators of gut-brain communication and may serve as potential therapeutic targets for neurodevelopmental and neurodegenerative disorders.

\section{Endocrine Regulation}

The HPA axis, as one of the main neuroendocrine systems in the human body, is a principal regulator of the response to stress [48]. In a pioneering study linking gut microbiota to the HPA axis, plasma adrenocorticotropic hormone and/or corticosterone elevation in response to restraint stress was more remarkable in adult GF mice than in specificpathogen-free (SPF) mice (with a normal composition of microbiota and no specific pathogens) [49]. The exaggerated stress response in GF mice could be partially reversed at 9 weeks of age by reconstitution with feces from the control mice [50]. Paradoxically, reduced anxiety-like behavior and central neurochemical change were observed in GF mice as compared to SPF mice [51]. Significant decrease in N-methylD-aspartate receptor subunit NR2B mRNA expression in the 
Fig. 2 Communication between gut microbiota and the brain. Communication pathways between gut microbiota and the brain include metabolic, endocrine, neural, and immunological pathways which can work independently or cooperatively: (1) gut microbiota metabolites, including SCFAs, neurotransmitters, and amyloids, may reach the brain to regulate neurological function; (2) gut microbiota interacts with the HPA axis, regulating brain function and gut microbiota composition; (3) direct activation of the vagus nerve from the enteric nervous system is transmitted to the brain; (4) MAMPs such as LPS can activate both the peripheral and the central immune system. Abbreviations: ACTH adrenocorticotropic hormone, $\mathrm{CRH}$ corticotropin-releasing hormone, $E C$ enterochromaffin cell, $E E C$ enteroendocrine cell, HPA hypothalamus-pituitary-adrenal, $L P S$ lipopolysaccharide, MAMPs microbial associated molecular patterns, SCFAs short-chain fatty acids, $V N$ vagus nerve

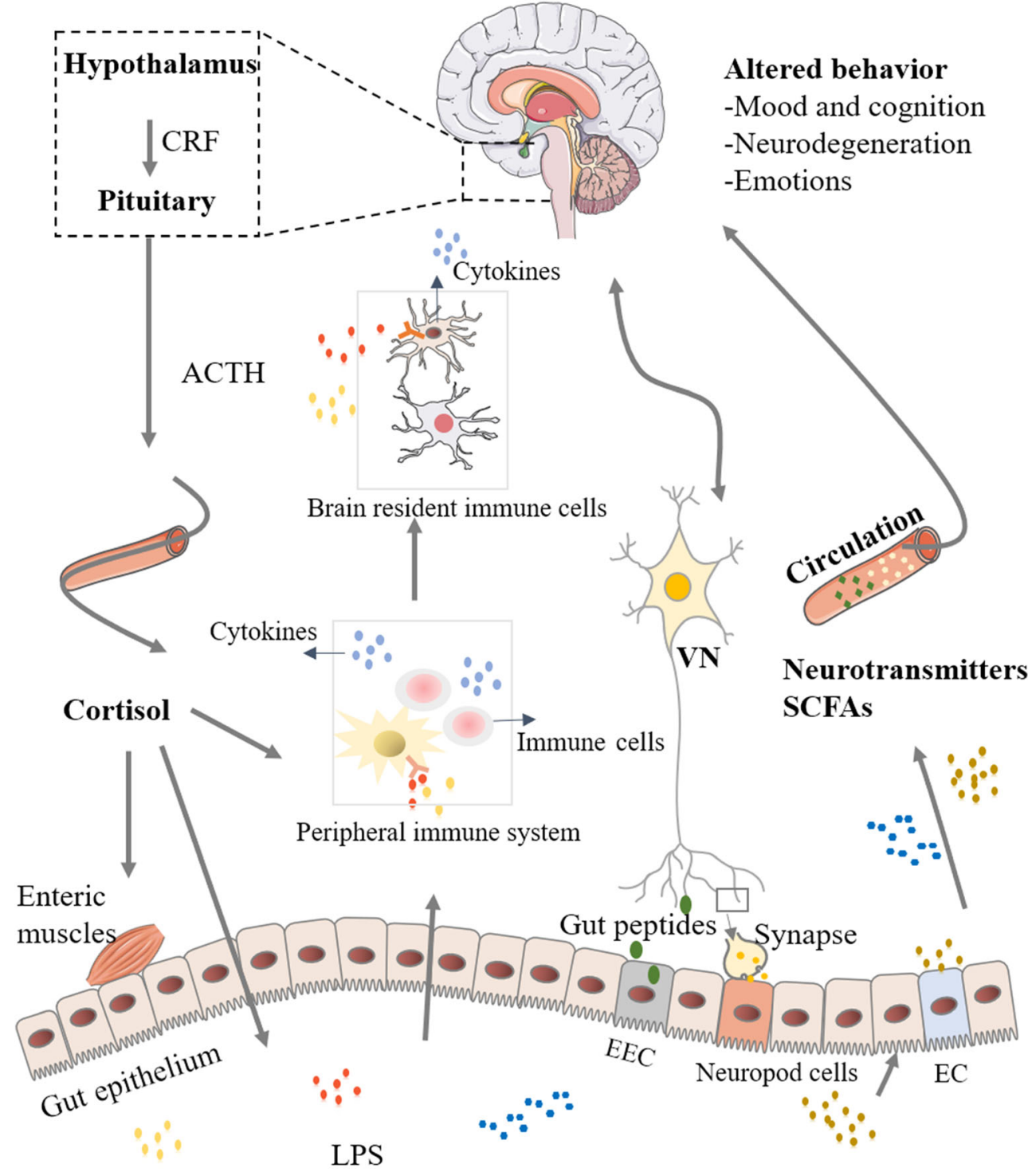

Amyloids

SCFAs

Neurotransmitters

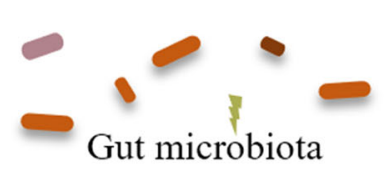

central amygdala and 5-hydroxytryptamine 1A receptor mRNA expression in the dentate gyrus may contribute to the altered HPA function in GF animals [51]. Although GF animals have been a cornerstone for investigating whether gut microbiota is involved in HPA axis regulation, they have many limitations in terms of dysregulated hormone signaling, aberrant neurodevelopment, and an impaired immune system due to a lack of exposure to microorganisms since birth [16]. Translational studies are therefore still limited, because no equivalent obliteration of gut microbiota can be conducted in humans.

\section{Neural Transmission}

The vagus nerve $(\mathrm{VN})$ originates in the medulla oblongata of the CNS and innervates numerous structures such as the heart and the GI tract, which is the key neural pathway between the gut and the brain, containing $80 \%$ and $20 \%$ of afferent and efferent fibers, respectively $[52,53]$. As a vast variety of chemical and mechanosensitive receptors are expressed on vagal afferents, and due to their role in interoceptive awareness, they respond to a variety of mechanical, chemical, and hormonal stimuli from gut microbiota and transfer gut 
Table 1 Common species of gut microbiota and effects of their metabolites on the central nervous system

\begin{tabular}{|c|c|c|c|}
\hline Gut microbiota & Metabolites & Effects on the central nervous system function & References \\
\hline Lactobacillus, Bifidobacterium & $\begin{array}{l}\text { Gamma-aminobutyric } \\
\text { acid (GABA) }\end{array}$ & $\begin{array}{l}\text { The predominant inhibitory neurotransmitter, } \\
\text { regulates mood, behavioral and cognitive functions }\end{array}$ & {$[37]$} \\
\hline $\begin{array}{l}\text { Bifidobacterium infantis, Streptococcus, } \\
\text { Escherichia, Enterococcus, Lactococcus, } \\
\text { Lactobacillus, Candida }\end{array}$ & Serotonin $(5-\mathrm{HT})$ & Neurotransmitters, regulate emotions & {$[38]$} \\
\hline $\begin{array}{l}\text { Escherichia, Bacillus, Lactococcus, } \\
\text { Lactobacillus, Streptococcus }\end{array}$ & Dopamine & $\begin{array}{l}\text { Regulate mental activities and motor functions, } \\
\text { cognitive functions such as learning and memory }\end{array}$ & {$[38]$} \\
\hline Lactobacillus, Bacillus & Acetylcholine & $\begin{array}{l}\text { Cognitive, memory, social life ability, self-care } \\
\text { ability, and emotional personality }\end{array}$ & {$[39]$} \\
\hline $\begin{array}{l}\text { Bacteroides, Bifidobacterium, Propionibacterium, } \\
\text { Eubacterium, Lactobacillus, Clostridium, } \\
\text { Roseburia, Prevotella }\end{array}$ & $\begin{array}{l}\text { Short-chain fatty } \\
\text { acids (SCFA) }\end{array}$ & $\begin{array}{l}\text { Decrease permeability of the blood-brain barrier (BBB), } \\
\text { promote the synthesis and secretion of neurotransmit- } \\
\text { ters } \\
\text { and hormones, reduce inflammation }\end{array}$ & {$[40]$} \\
\hline $\begin{array}{l}\text { Lactococcus, Lactobacillus, Streptococcus, } \\
\text { Enterococcus }\end{array}$ & Histamine & Regulate sleep and cognition & {$[41,42]$} \\
\hline
\end{tabular}

information to the CNS [54]. However, this chemo- and mechanosensitive perception cannot be conducted directly, because vagal afferents do not cross the epithelial layer [55]. Interestingly, a subtype of gut enteroendocrine cells (EECs) were found to synapse with vagal neurons and transmit the information to the brain directly; these EECs were named neuropod cells [56]. Perhaps the most striking observation regarding the role of the $\mathrm{VN}$ in the microbiota-gut-brain axis comes from vagotomy studies. Mice treated with Lactobacillus rhamnosus showed reduced anxiety- and depression-related behavior, which was not observed in mice with VN ablation [57]. Furthermore, vagotomy reduced the proliferation and survival of newborn cells and decreased the number of immature neurons and the activation of microglia in the dentate gyrus of the hippocampus [58]. Whether VN targeting by stimulation or vagotomy translates to microbialbased CNS therapeutics remains a tempting possibility and merits further investigation.

\section{Immunomodulation}

The densest concentration of immune cells, such as B cells, T cells, macrophages, and dendritic cells, is found in the intestine. Gut microbiota can profoundly affect the development of organized lymphoid structures and the activation of both the innate and adaptive immune systems [59, 60]. Microbiota-host immune interactions in the gut lead to the release of proinflammatory mediators, e.g., cytokines and chemokines, and specific antibodies involved in the regulation of brain immunity. Metabolites produced by gut microbiota also regulate the maturation, differentiation, and activation of microglia and astrocytes, which mediate several neurophysiological processes, including maintenance of blood-brain-barrier (BBB) integrity, neural development, neurotransmission, and CNS immune activation $[61,62]$. Therefore, a complex immunoregulatory network of interactions exists among gut microbiota, the intestinal mucosal immune system, and the brain.

\section{Roles of the Microbiota-Gut-Brain Axis in the Pathogenesis of AD}

Alterations of gut microbiota in animals and patients with AD are summarized in Table 2. Key questions as to how the axis contributes to the onset and/or progression of $\mathrm{AD}$, however, remain unanswered. In this section, we review the roles of the microbiota-gut-brain axis in the pathogenesis of AD so as to elucidate the possible pathophysiological mechanism underlying the modulation of gut microbiota in $\mathrm{AD}$ (Fig. 3).

\section{Associations Between the Microbiota-Gut-Brain Axis and $A \beta$ Accumulation}

Neurological disorders such as AD, Parkinson's disease (PD), and amyotrophic lateral sclerosis are characterized by the gradual accumulation of abnormal proteins in the CNS [72]. The proclamation "all disease begins in the gut," purported by the Greek physician Hippocrates 2000 years ago, has been an intriguing one and continues to influence medical researchers and practitioners [16]. One hypothesis regarding the pathogenesis of PD claims that the initial induction and subsequent aggregation of $\alpha$-synuclein probably originate in the enteric nervous system and spread upwards progressively to the CNS, propagating trans-synaptically from nerve cell to nerve cell in a virtually self-promoting pathological process [73]. Gut dysbiosis is mainly characterized by an increase in the Firmicutes/Bacteroidetes ratio, which could cause intestinal APP accumulation since the earliest stages of AD [74]. Changes in the composition of gut microbiota in APP/PS1 mice were related to an increase in $A \beta$ levels in the $C N S$ 
Table 2 Summary of studies concerning the alterations of the gut microbiota in $\mathrm{AD}$

\begin{tabular}{|c|c|c|c|}
\hline Experimental subject & Methods & Main findings & Reference \\
\hline $\begin{array}{l}\text { Patients with cognitive impairment } \\
\text { and brain amyloidosis }\end{array}$ & Microbial DNA qPCR assay & Escherichia/Shigella $\uparrow$, E. rectale $\downarrow$ & {$[63]$} \\
\hline AD patients & 16S rRNA sequencing & $\begin{array}{l}\text { Bacteroides, Actinobacteria, Ruminococcus, } \\
\text { Lachnospiraceae, and Selenomonadales } \\
\text { at taxonomic levels }\end{array}$ & {$[64]$} \\
\hline AD patients & 16S rRNA sequencing & Firmicutes and Bifidobacterium $\downarrow$, Bacteroidetes $\uparrow$ & {$[65]$} \\
\hline AD patients & PCR & $\begin{array}{l}\text { Significant difference in the gut microbial genotypes } \\
\text { between the AD and control human populations }\end{array}$ & {$[66]$} \\
\hline AD patients & 16S rRNA sequencing & Bacterial population in the brain $\uparrow$ & {$[67]$} \\
\hline APP/PS1 transgenic mice & 16S rRNA sequencing & The microbiota composition and diversity were perturbed & {$[68]$} \\
\hline APP/PS1 transgenic mice & 16S rRNA sequencing & $\begin{array}{l}\text { Proteobacteria and Erysipelotrichaceae increased with age. } \\
\text { Total Bacteroidetes remain stable. The inflammation-related } \\
\text { family Erysipelotrichaceae was more abundant in aging }\end{array}$ & {$[69]$} \\
\hline APP/PS1 transgenic mice & 16S rRNA sequencing & $\begin{array}{l}\text { Microbiota diversity was decreased } \\
\text { Odoribacter and Helicobacter } \uparrow\end{array}$ & {$[70]$} \\
\hline Symptomatic Tg2576 mice & 16S rRNA sequencing & $\begin{array}{l}\text { The percentage abundance of Firmicutes and Bacteroidetes } \\
\text { phyla was significantly higher. Lactobacillusi } \uparrow\end{array}$ & {$[71]$} \\
\hline
\end{tabular}

and impaired spatial learning and memory [70]. Moreover, aberrant accumulation of $\mathrm{A} \beta$ in myenteric neurons and activation of intestinal innate immunity appear before the onset of CNS neuroinflammation in AD mice [75]. Likewise, gut dysbiosis, intestinal epithelial barrier dysfunction, and vascu$\operatorname{lar} \mathrm{A} \beta$ deposition in the gut occur before the onset of cerebral $\mathrm{A} \beta$ depositions in Tg2576 mice (a transgenic mouse model of AD) [71]. The presence of $A \beta$ deposits is also noted in intestinal autopsies of patients with AD [71]. Hence, a hypothesis which assumed that $A \beta$ accumulation in the gut precedes that in the brain came into being. However, research aimed at elucidating the relationship between gut dysbiosis, intestinal $\mathrm{A} \beta$ accumulation, and $\mathrm{AD}$ onset is lacking and a causal relationship between them has not been established. Early manipulation of gut physiology and microbiota as a means to possibly reverse the pathology of $\mathrm{AD}$ needs further investigation.

Another possible mechanism is related to the release of certain bacterial metabolites by gut microbiota. SCFAs demonstrate efficacy in interfering with protein-protein interactions that are indispensable for $\mathrm{A} \beta$ assemblies [76]. The microbial-derived metabolite trimethylamine $\mathrm{N}$-oxide (TMAO) has been implicated in the pathogenesis of $\mathrm{AD}$ as well [77]. TMAO causes cognitive deterioration and pathological processes in AD by increasing $\beta$-secretase activity and thus aggravating $A \beta$ accumulation [77]. Moreover, gut microbiota, through the generation of TMAO, contributes to platelet hyperreactivity by enhancing the stimulus-dependent release of calcium ions from intracellular stores, promoting the $A \beta$ produced in platelets to enter the circulation and reach the brain [78-80]. Through a mechanism very similar to that of prion molecules, $A \beta$ may seed in the brain from neuron to neuron, contributing to the progression of cytopathological lesions in AD [72]. These data suggest that specific personalized nutrition interventions might represent an effective strategy to modify the production and aggregation of $A \beta$.

Increased circulating bacterially produced bile acids (BAs) may increase BBB permeability via the disruption of tight junctions [81, 82] and permit BAs or peripheral cholesterol to reach the CNS [83]. Mounting cellular cholesterol in the brain leads to direct binding to APP and thus facilitates APP insertion into the phospholipid monolayers of the lipid rafts where $A \beta$ formation takes place, eventually promoting the production of $A \beta$ [84]. More importantly, cholesterol accumulation in the brain may be induced via effects mediated by BAs on the farnesoid $\mathrm{X}$ receptor, which downregulates the expression of the cholesterol-metabolizing enzyme CYP46A [85]. From this perspective, BAs perturb cholesterol elimination pathways, cause cholesterol accumulation, and further increase $\mathrm{A} \beta$ production. Of note is the contribution of bacterial amyloids to $A \beta$ accumulation. A well-described bacterial amyloid is curli, which is produced by Escherichia coli. Through molecular mimicry, bacterial amyloids may act as prion proteins to cross-seed and aggregate host amyloids [86]. Other amyloids produced by microbes include FapC by Pseudomonas fluorescens, phenol-soluble modulins by Staphylococcus aureus, chaplins by Streptomyces coelicolor, and MccE492 by Klebsiella pneumonia [87].

Microglial activation is associated with AD pathology [88] and phagocytic microglia are crucial for the uptake and engulfment of soluble $A \beta$ species and the phagocytosis of insoluble fibrillar $A \beta$ deposits [89]. Activated microglia clustering around amyloid deposits may constitute a barrier that can compact amyloids, minimize damage to adjacent neuropils, and decrease the incorporation of new neurotoxic $A \beta$ into existing plaques [90]. Notably, gut microbiota appears to be a prerequisite for microglia maturation and function under homeostatic 


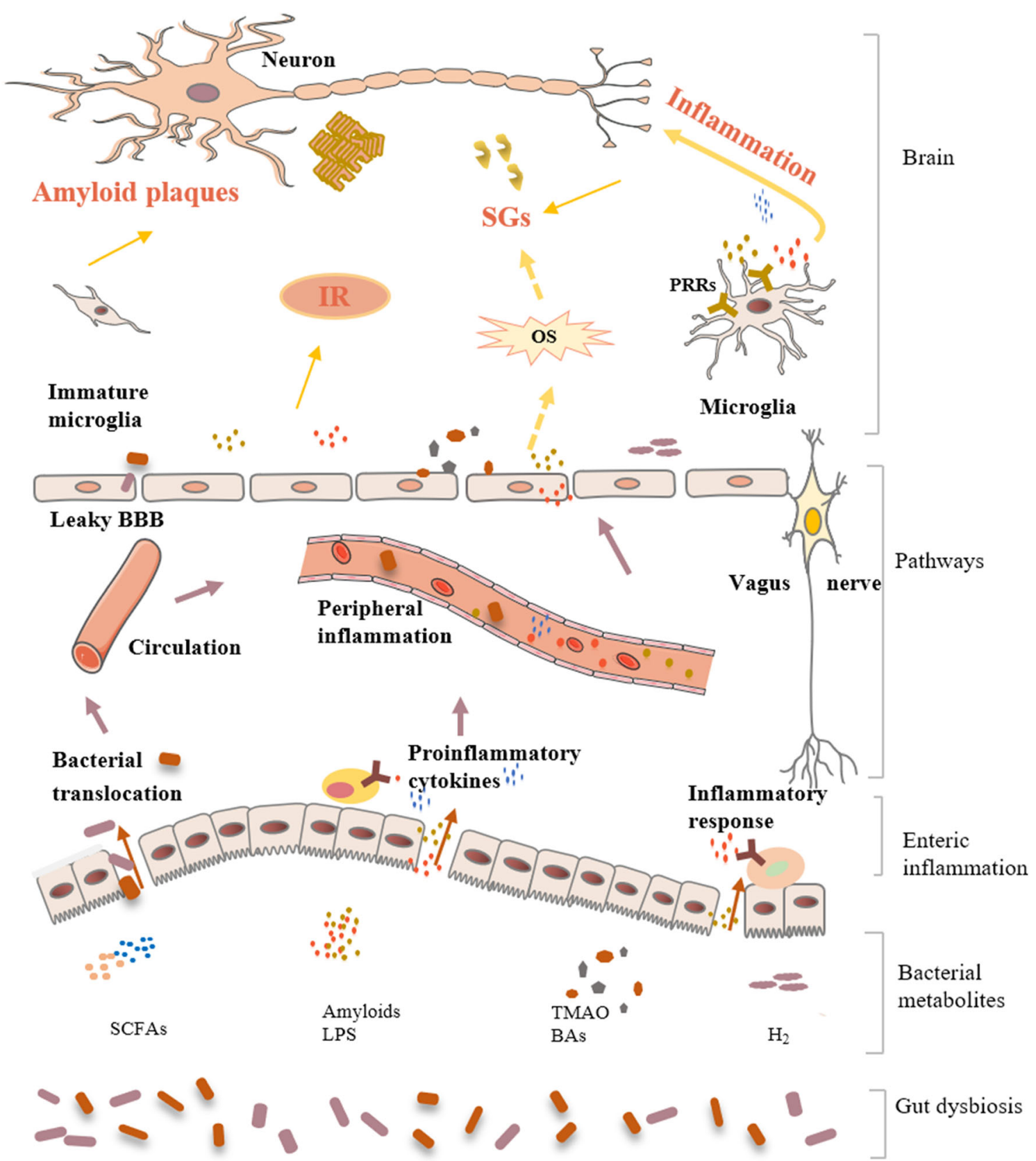

Fig. 3 Impact of gut dysbiosis on AD. Gut dysbiosis induces the decrease of beneficial substances (such as SCFAs and $\mathrm{H}_{2}$ ) and the increase of harmful substances (such as amyloids and TMAO), which causes the intestinal mucosal barrier and BBB to become permeable, activates peripheral immune responses, and increases peripheral and central OS levels. Finally, gut dysbiosis contributes to $\mathrm{AD}$ pathology progression by increasing amyloid plaque formation, neuroinflammation, SGs, and

conditions [61]. GF mice and SPF mice, both with reduced gut microbiota complexity, displayed defects in microglia characterized by altered cell proportions and immature phenotypes which could successfully be rescued by supplementation with SCFAs or by re-introducing live and complex microbiota, respectively [61]. Microglia from adult GF mice also exhibited downregulated expression of genes associated with microglial
IR. Arrows indicate the direction of the effect. Yellow arrows with dashed lines indicate that no studies have explored this putative relationship yet in the AD-gut microbiome field. Abbreviations: $A D$ Alzheimer's disease, $B A s$ bile acids, $B B B$ blood-brain barrier, $L P S$ lipopolysaccharide, $\mathrm{H}_{2}$ hydrogen, $I R$ insulin resistance, $O S$ oxidative stress, PRRs patternrecognition receptors, $S C F A s$ short-chain fatty acids, $S G s$ stress granules, TMAO trimethylamine $\mathrm{N}$-oxide

maturation [61]. Microglia in SPF mice lacking free fatty acid receptor 2 (a SCFA receptor) displayed a phenotype nearly identical to that observed in GF mice [61]. These findings suggest that microglia are highly sensitive to perturbations in the gut microbial community and metabolites.

Taken together, although the pathogenic role of $A \beta$ in the pathogenesis of $\mathrm{AD}$ needs to be further clarified, gut dysbiosis 
may contribute to the neuronal damage in $\mathrm{AD}$ in an $\mathrm{A} \beta$ dependent mechanism. Future research should focus on whether gut microbiota represents an important hinge between $\mathrm{AD}$ and its risk factors.

\section{Neuroinflammation and Microbiota-Mediated Alteration of BBB Permeability}

The BBB is a multilayered unit, comprising specialized brain endothelial cells linked by tight protein junctions in the microvasculature, which acts as a semipermeable barrier to control the passage and exchange of molecules and nutrients between the circulatory system and the brain parenchyma [91]. Structural and functional disruption of the BBB in AD may be an early and important step in the pathogenesis [92]. A pioneering study reported that GF mice showed increased permeability of the BBB, which may partly be the consequence of disorganized tight junctions due to reduced expression of tight junction proteins, especially occludin and claudin-5; the reduced BBB permeability could be restored by recolonization of gut microbiota, implying a causal role for gut microbiota in ensuring the development of the BBB [93]. SCFAs can enter the circulation and decrease the permeability of the BBB by increasing the expression of endothelial tight junction proteins, especially occludin and claudin-5 [93, 94]. A propionate concentration as low as $1 \mu \mathrm{m}$ can protect the BBB from OS by an NFE2L2-dependent mechanism [95]. These findings implicate the ability of gut microbiota to affect the permeability of the BBB. Impaired intestinal epithelial barrier integrity may permit unregulated translocation of pathogenic microbiota out of the gut, which then undergoes dissemination in the CNS via the impaired BBB [96]. Compared with those from control groups, brain samples from patients with $\mathrm{AD}$ showed an increase in bacterial populations [67]. Several studies have revived interest in a long-standing hypothesis that there may be a possible microbial origin for $\mathrm{AD}[97,98]$. One piece of seminal evidence is that $A \beta$ exhibits characteristics of an anti-microbial peptide which is active against at least 12 different microorganisms [99]. Intriguingly, Salmonella typhimurium bacterial infection of the brains of 4-week-old $5 \mathrm{xFAD}$ mice led to the presence of $\mathrm{A} \beta$ in brain parenchyma, where it closely colocalized with the bacterial deposition [100]. Similarly, increased A $\beta$ deposition was present in brain parenchyma sites containing deposits of herpes simplex virus type 1 [101]. However, it is ethically challenging for validation studies conducted on humans.

Gut microbiota also produces a remarkably complex array of proinflammatory neurotoxins that can cross the BBB and are pathogenic and highly detrimental to the homeostatic function of neurons in the CNS [16]. In particular, the role of lipopolysaccharide (LPS) generated by Gram-negative bacteria is relatively well documented. Bacterial LPS can bind with microglial cell receptors (TLR2, TLR4, and/or CD14) to initiate the production of a cascade of cytokines and chemokines via myeloid differentiation factor 88 (MyD88) and nuclear factor kappa beta (NF-KB)-dependent signaling pathways [102, 103]. Interestingly, the presence of LPS has been detected in the neocortex and hippocampus of patients with AD [104]. In a rodent model, TLR4 inhibited proliferation and neuronal differentiation upon LPS binding, while TLR2 enhanced hippocampal neurogenesis [105]. LPS appeared to efficiently activate $\mathrm{NF}-\mathrm{KB}$ signaling to increase the levels of proinflammatory miRNA-146a and miRNA-155, which resulted in the downregulation of complement factor $\mathrm{H}$ expression and contributed to the onset of $\mathrm{AD}$ [106]. The inflammasome is a cytosolic macromolecular signaling platform which mediates activation of the cysteine protease caspase-1, leading to proteolytic processing and secretion of the proinflammatory cytokines interleukin (IL)-1 $\beta$ and IL-18 [107]. Inflammasome-mediated inflammation may represent a critical component of the inflammatory response in $\mathrm{AD}$ [108]. Extracellular LPS has also been reported to trigger microglial NOD-like receptor protein (NLRP)3 inflammasome activation [109]. Therefore, bacterial endotoxins may be internal contributors to inflammatory degeneration in the CNS. Aside from glial subsets, innate and adaptive immune cells, including perivascular macrophages, $\mathrm{CD}^{+} \mathrm{T}$ and $\mathrm{CD} 8^{+} \mathrm{T}$ cells, and mast cells, are also resident in the CNS [62].

Systemic inflammation is likely to interfere with the immunological processes of the brain and further promote AD progression. This hypothesis is supported by clinical studies of $\mathrm{AD}$ showing increased cognitive decline and exacerbation of neurodegeneration following acute and chronic systemic inflammation $[110,111]$. Increase in levels of the proinflammatory bacteria Escherichia/Shigella and reduction in the levels of the anti-inflammatory bacteria Eubacterium rectale are associated with increased levels of IL-1 $\beta$, CXCL2, and NLRP3 in the plasma of patients with cognitive impairment and brain amyloidosis [63]. The intestinal mucosal lymphoid tissue is regarded as the largest and most important human immune organ, containing 70-80\% of the immune system of the whole body [112]. Microbe-associated molecular patterns (MAMPs) such as LPS can bind with various pattern-recognition receptors expressed on macrophages and dendritic cells in the gut, resulting in the production of inflammatory mediators such as proinflammatory cytokines [113]. A more permeable intestinal epithelial barrier permits these inflammatory mediators to enter the circulatory system and cause systemic inflammation [96]. Microbe-derived metabolites are additional contributors to systemic inflammation; for example, alterations of gut microbiota could lead to elevation of phenylalanine and isoleucine concentrations in the periphery of $\mathrm{AD}$ mice, which could provoke the infiltration of various immune cells, including $\mathrm{T}$ cells, B cells, natural killer cells, neutrophils, dendritic cells, and monocytes; $\mathrm{CD}^{+}{ }^{+} \mathrm{T}$ helper (Th) 1 cell levels were 
significantly correlated with M1 microglial activation in the brain during the progression of $\mathrm{AD}$ [114].

$\mathrm{TBI}$ is an important risk factor for developing $\mathrm{AD}$ later in life, though the mechanism behind this correlation is still unclear [10]. Gut microbiota may serve as a potential hub linking TBI, inflammation, and AD. Significant changes in gut microbiota composition at the genus and species level in injured mice highlighted the high probability of gut dysbiosis after TBI [115]. The systemic inflammatory response resulting from gut dysbiosis exerts an influence on the vulnerable and primed microglia following brain injury to further exacerbate neuroinflammation, which in turn predisposes or accelerates the onset and progression AD [116]. Similarly, gut microbiota may also be involved in a potential nexus between chronic psychological stress, inflammation, and AD. The HPA axis plays a significant role in the host's response and adaptation to stress. Observations of elevated basal cortisol levels in patients with $\mathrm{AD}$ prompted the hypothesis that stress may predispose the brain to neurodegeneration [117]. Indeed, chronic psychological stress leads to microglial activation, characterized by an exaggerated release of proinflammatory cytokines and chemokines [118]. Physiological stress may alter the integrity of the intestinal epithelial barrier and the composition of gut microbiota in association with release of proinflammatory cytokines, such as IL-1 $\beta[96,119]$, that could activate the HPA axis; in this manner, gut microbiota can dramatically modify the body's responsiveness to stress $[49,50]$. In this perspective, gut microbiota located at the key position in the stress-inflammation loop might be actively involved in neuroinflammation and $\mathrm{AD}$ pathogenesis.

\section{Does Gut Microbiota Modulate OS?}

Non-polysomal RNA and mRNA-binding proteins (RBPs) are the major components of stress granules (SGs), which form through a process of liquid-liquid phase separation (LLPS) when exposed to multiple types of stresses [120]. SGs are generally dynamic structures that rapidly form and disassemble with acute stress, while persistent SGs form as a consequence of chronic environmental stress and have been implicated in the pathogenesis of $\mathrm{AD}$ [121].

SGs may even be the breeding ground for the aberrant aggregation of pathological tau $[121,122]$. Interactions between tau and SGs stimulate the formation of tau aggregates [123]. Tau undergoes LLPS with RNA and forms tau droplets which turn into aggregates to create the initial site of filament assembly, a process associated with AD pathogenesis [124]. SGs have a high concentration of mRNA, which probably enhances the conversion of tau into droplets [122]. Importantly, tau co-localizes strongly with RBPs and does not undergo LLPS in the absence of RBPs [121]. These findings advance our understanding of how these processes trigger tau protein aggregation and accelerate $\mathrm{AD}$ pathophysiology.
OS represents a condition of imbalance between the accumulation and elimination of ROS, which has various deleterious effects on the body [125]. OS is a well-recognized condition that facilitates SG formation [126]. Gut microbiota may influence the levels of OS in the CNS either by increasing the oxidant components or by interfering with anti-oxidant systems [127]. Gut microbiota promotes ROS generation within the gut epithelia [128], which in turn disturbs gut microbiota composition and functionality and makes the intestinal epithelial barrier more permeable $[129,130]$. Neurotoxic substances such as LPS may reach the CNS via the VN or systemic circulation, promoting microglial activation and neuroinflammation, which produces even more ROS [131]. Another mechanism is mostly speculative but is pertinent to the hypothesis that the oxidative state of the CNS could be regulated by gut microbiota via the production of various metabolites. Decreased butyrate levels could impair mitochondrial functions, resulting in significant ROS production in Crohn's disease [132]. Similarly, we speculate that the relative abundance of butyrate producers may cause mitochondrial dysfunction in the brain and increased production of ROS. Hydrogen $\left(\mathrm{H}_{2}\right)$, a highly diffusible bioactive gas with anti-oxidant properties, was found to be produced mainly by strains of the genus Clostridium, anaerobic cocci, and members of the Enterobacteriaceae family [133]. Gut dysbiosis may result in low $\mathrm{H}_{2}$ production in the gut, and less gas is subsequently transferred to the portal vein, limiting the availability of the gas in the CNS [133]. Alterations of gut microbiota may in this regard interfere with the intracranial OS level and further favor SG formation. SGs have progressively gained recognition as essential contributors to the pathogenesis of $\mathrm{AD} \mathrm{[121],}$ which provides a new dimension to the understanding of gut microbiota and $\mathrm{AD}$ pathogenesis.

\section{Does Gut Microbiota Affect AD Progression Via IR?}

Compelling preclinical and clinical evidence supports the hypothesis that impaired insulin signaling may be associated with AD pathogenesis [134]. Considerable overlap has been identified in the molecular, biological, pathophysiological, and metabolic dysfunctions in AD and T2DM. IR is the disturbance of glucose regulation characterized by higher insulin levels. As a consequence of tissue desensitization to the action of insulin, IR occurs in peripheral tissues in patients with diabetes and obesity and has recently been shown to develop in AD brains [135]. In light of these observations, AD has also been termed as "type 3 diabetes," which is viewed in a sense as a degenerative metabolic disease [136]. However, insulin signaling impairment has been observed even in the brains of patients with $\mathrm{AD}$ who are not diabetic [137]. Whether IR in $\mathrm{AD}$ and $\mathrm{T} 2 \mathrm{DM}$ is a parallel phenomenon arising from coincidental roots in aging or whether there is an underlying mechanistic link is unclear. 
Colonization of GF mice with gut microbial communities harvested from $o b / o b$ mice resulted in increased body fat associated with IR [138]. Moreover, interventions involving probiotics and antibiotics improved insulin signaling and strengthened glucose control [139, 140]. Alterations in gut microbiota can modulate behaviors through the regulation of brain insulin sensitivity. Increased brain insulin signaling sensitivity and reduced signs of anxiety and depression were observed in mice with diet-induced obesity treated with oral metronidazole or vancomycin [141]. Furthermore, manipulation of gut microbiota through oral administration of probiotics ameliorated impaired glucose metabolism and cognitive dysfunction in a mouse model of AD [142]. The current data therefore allow us to hypothesize that changes in gut microbiota may contribute to IR in patients with AD. Future research efforts should be dedicated to better clarify the causal relationship between gut microbiota, IR, and AD. The phenomenon of IR is essential to our understanding of the overlap between AD and T2DM. Given the cause-effect relationship between gut microbiota and IR, T2DM and AD may be parallel diseases arising from the same fundamental aging-related alterations in gut microbiota.

\section{Potential Therapeutic Strategies for AD Targeting the Microbiota-Gut-Brain Axis}

\section{Diet}

Diet represents a pivotal determinant of gut bacterial assembly and genetic composition [143]. Specific foods and dietary patterns can influence the composition and abundance of different types of bacteria in the gut, which can in turn maintain host homeostasis. The Mediterranean diet (MD), which includes high-level consumption of fruits, vegetables, legumes, and cereals, has long been described as a healthy dietary pattern $[16,17]$. Higher MD slowed the progression of AD and conferred protection of 1.5 to 3.5 years against AD [144]. The MD confers anti-inflammatory effects which are often linked with an increase in Bacteroides and Clostridium phyla and decrease in Proteobacteria and Bacillaceae phyla [145]. Human intervention studies suggest that high-level consumption of plant-based food consistent with the MD can modulate the gut microbiome composition, increase fecal SCFA levels, and decrease urinary TMAO levels [146]. Microbiotaaccessible carbohydrate supplementation could ameliorate Western diet-induced gut dysbiosis, intestinal epithelial barrier impairment, and systemic inflammation in mice [147]. Furthermore, microbiota-accessible carbohydrate supplementation reduced neuroglial activation and synaptic impairment, which were eliminated with the depletion of gut microbiota using wide spectrum antibiotics [147]. The MD may serve as a potential therapeutic intervention in the treatment of $\mathrm{AD}$ by modulating gut microbiota. Such healthy diets merit investigation for their potential benefits with regard to brain disorders. However, much more work is still needed to determine how diet and its components imbue their effects on the microbiota-gut-brain axis and to delineate whether the effects of diets on microbiota drive changes in overall brain function.

\section{Pharmacological Strategies}

Disease-modifying therapies are still lacking for AD [148]. One of the latest intriguing breakthroughs is GV-971, a sodium oligomannate extracted from algae that has been demonstrated to result in robust and consistent cognitive improvements in a phase 3 clinical trial [114]. GV-971 was found to significantly decrease microglial activation and multiple brain proinflammatory cytokine levels by altering the composition of gut microbiota and reducing the peripheral concentrations of phenylalanine and isoleucine generated by gut microbiota [114]. The underlying mechanism of GV-971 that improves cognition via alleviation of neuroinflammation inspires us to attempt to reduce peripheral phenylalanine and isoleucine concentrations directly by diet or pharmacological strategies instead of regulating gut microbiota.

Neurotransmitters including acetylcholine, GABA, histamine, and serotonin, which can be produced by gut microbiota, are critical modulators to regulate the gut-brain axis and play a crucial role in AD pathogenesis [149]. Exogenous manipulation of the serum concentrations of these neurotransmitters by targeting the appropriate receptors or blocking their breakdown may benefit decreased symptomology and/or disease progression. The United States Food and Drug Administration has approved four acetylcholinesterase inhibitors (AChEIs), tacrine, donepezil, rivastigmine, and galantamine, for "disease-modifying" effects on AD [150]. Several different clinical trials on novel AChEIs and acetylcholine stimulation in $\mathrm{AD}$ are ongoing, with the purpose of evaluating the efficacy, safety, tolerability, and pharmacokinetics of these drugs [151]. Ongoing studies are also being conducted to test the possibility of using GABA modulators and GABA agonists as $\mathrm{AD}$ therapeutics [151]. H3 receptor antagonists/ inverse agonist molecules could inhibit histamine release and reverse partial cognitive function loss in animal models [152]. Various serotonin-mimetic compounds, selective serotonin reuptake inhibitors, and 5-HT receptor agonists or antagonists were proven to be safe and also improved cognitive disturbances. So far, no metabolite-based therapies associated with neurotransmitters are available to prevent disease processes and/or relieve the cognitive functions in patients with AD. Given the complex and significant role of neurotransmitters in $\mathrm{AD}$ pathogenesis, research exploring the therapeutic potential of neurotransmitters AD cannot be ignored. However, multiple cohort and longitudinal studies are still needed to this end. 


\section{Probiotics}

The term "probiotics" was first coined in 1974 and has conceptually evolved to its current definition as "live microorganisms that modify microbiota toward a beneficial state" [153]. Beneficial effects of probiotic supplementation include induction of immunomodulation, protection against physiological stress, pathogen antagonism, and improvement of the intestinal epithelial barrier function [154]. Mice treated with probiotics showed increased spatial memory and significantly lower quantities of plaques in the hippocampus [155]. Probiotic supplementation could also considerably improve synaptic plasticity and significantly restore long-term potentiation in the $A \beta$ administered animals [156]. With long-term oral ProBiotic-4 (a complex probiotic preparation) administration, senescenceaccelerated mouse prone 8 mice showed significant improvement in microbiota composition of the feces and brain, cerebral neuronal and synaptic injuries, and immune response activation [157]. The underlying mechanism is related to inhibition of both TLR4- and retinoic-acid-inducible gene-I-mediated NF-KB signaling pathways in the brain [157]. At present, only one clinical trial has been conducted to assess the effects of probiotic supplementation on AD [158]. Patients with AD provided with probiotics showed improvement in cognitive function and favorable changes in related plasma biomarkers such as malondialdehyde and serum triglyceride [158]. These findings suggest that probiotic supplementation may have the therapeutic potentials to block or reverse the progression of $\mathrm{AD}$. However, clinical evidence is insufficient to reach conclusions regarding the recommendation of probiotics for patients with AD. The exact mechanism by which probiotics display effects in $\mathrm{AD}$ remains unclear. Probiotic supplementation in humans did not seem to change the composition of intestinal flora (at least based on 16s rRNA sequencing) but induced the effect of probiotics on behavior by temporarily changing the transcriptional state of the collective microbiome, which was later confirmed in GF mice and monozygotic twins [159].

Metatranscriptomic and metabolomic technologies are needed to assess the effects of probiotic intervention on gut microbiota in the host. Although probiotics have been widely promoted among the general public, many probiotic strains and formulations have contradictory clinical results [154]. More attention should be paid to the adverse effects of probiotics, which include systemic infection, GI side effects, gene transfer from probiotics to normal microbiota, harmful metabolic effects of probiotics, immune system stimulation, etc. [160]. Besides, future probiotic therapy for $\mathrm{AD}$ requires the development of means to tackle colonization resistance [154].

\section{Prebiotics}

The current definition of prebiotics is "a substrate that is selectively utilized by host micro-organisms and confers a health benefit," proposed by the International Scientific Association for Probiotics and Prebiotics [153]. Several different kinds of food ingredients are considered prebiotics, among which resistant starch (RS), insulin, fructooligosaccharides (FOS), galactooligosaccharides, and xylooligosaccharides are most frequently highlighted [161]. RS is known to exert a powerful influence on metabolic and systemic health and has been extensively studied in clinical trials and animal models for evaluating treatment potential [162]. RS2 has been shown to alter the abundance of at least some intestinal bacterial genera and species, including enrichment of Ruminococcus bromii, Bifidobacterium adolescentis, Faecalibacterium prausnitzii, and E. rectale and reductions in Oscillospira, Lachnospiraceae, and Blautia [163]. FOS are found in natural fruits and vegetables and can promote the growth of beneficial gut microbiota such as Bifidobacterium and Lactobacillus [164, 165]. FOS are effective in maintaining the diversity and stability of the microbial community, alleviating neuronal apoptosis and the swelling of brain tissues, regulating the synthesis and secretion of neurotransmitters, and downregulating the expression of tau and $A \beta 1-42$ in the brain of rats with AD-like symptoms [166]. These findings suggest that the therapeutic effect of FOS on AD is at least partially mediated by targeting of the microbiota-gut-brain axis. Furthermore, FOS exerted beneficial effects against $\mathrm{AD}$ via regulating the gut microbiota glucagon-like peptide-1 (GLP-1)/GLP-1 receptor pathway in APP/PS1 transgenic mice [167]. In humans, prebiotic supplementation exerts relatively modest effects on the microbiota and alters the expression level of cytokine genes, which may be beneficial for the elderly [168]. Although nurturing beneficial gut microbiota using prebiotics may provide major benefits, basic knowledge on the delicate interactions between the host, gut microbiota, and prebiotics is still lacking. Many technical and pragmatic difficulties, such as ensuring it reaches the location where it can exert its potential therapeutic effect, remain to be solved. Randomized controlled studies with larger cohorts are needed to evaluate the effect of prebiotics in patients with $\mathrm{AD}$ and to provide clinical evidence that can be translated into clinical practice.

\section{Fecal Microbial Transplantation}

Fecal microbial transplantation (FMT) is the transfer of prescreened donor stool into the GI tract of patients with the aim of increasing overall diversity and restoring the function of gut microbiota $[169,170]$. At present, FMT is only recommended as a treatment for recurrent Clostridium difficile infection, although trials on human diseases ranging from inflammatory bowel disease to metabolic diseases, neurodegenerative diseases, and cancer are ongoing worldwide. FMT 
could improve cognitive deficits and lessen $\mathrm{A} \beta$ deposition in the brain of AD animals [171]. Frequent transfer and transplantation of fecal microbiota from WT mice to ADLP ${ }^{\mathrm{APT}}$ mice reduced amyloid plaque and NFT formation, glial responses, and cognitive impairment; FMT reversed the abnormal expression of intestinal macrophage activity-related genes and the increase of circulating blood inflammatory monocytes in $\mathrm{ADLP}^{\mathrm{APT}}$ recipient mice [19]. Given that fecal material is expected to be sourced perfectly from a highly organized stool bank and various routes of administration such as capsule, enema, or colonoscopy [172], opportunities to exploit FMT to treat $\mathrm{AD}$ are materializing and FMT may be significantly convenient and efficacious. However, due to the inherent limitations of rodent models of human brain disorders, it is advisable to caution against premature extrapolation from preclinical data. FMT clearly poses significant unique and complex challenges for both clinicians and regulators, including its poorly defined mechanisms of action, stool availability, donor selection, adverse effects, and the relative lack of long-term follow-up data. Technical standardization, safety assessment, stool bank services and management, and other aspects are still in their infancy and need to be further studied. In this context, the FMT methodology is gaining considerable attention in both preclinical and clinical research and is likely to develop rapidly over the next decade.

\section{Conclusions and Perspectives}

Gut microbiota can modulate important processes, including microglia maturation and activation, neurogenesis, myelination, synaptic pruning, and BBB permeability. The microbiota-gut-brain axis links gut microbiota and the brain via metabolic, endocrine, neural, and immune pathways that are crucial for the maintenance of brain homeostasis. Emerging evidence indicates that gut dysbiosis may aggravate $A \beta$ aggregation and neuroinflammation in the development of AD. Restoring and remodeling gut microbiota composition may result in a strategic breakthrough in the treatment and, more importantly, the prevention of $\mathrm{AD}$.

The development of cheaper and faster sequencing and other biological techniques has provided new insights into the characterization of gut microbiota. Human studies exploring biocommunication pathways between microbiota and the brain over time have flourished thereafter. However, some key issues need to be addressed in the future. First, the definition of normal or healthy microbiome may be one of the biggest challenges. A better description of microbial community dynamics and metabolism will help demarcate "normal" and "abnormal" human gut microbiota and identify therapeutic targets for AD. Second, factors like diet, drugs, and health status may confound the research on gut microbiota and AD.
Cross-sectional clinical studies have demonstrated specific changes in the composition and functionality of gut microbiota in patients with AD. Longitudinal studies combining metagenomics sequencing and in-depth phylogenetic analysis with a comprehensive phenotypic characterization of patients with $\mathrm{AD}$ using up-to-date omics (metagenomics, metabolomics, transcriptomics, and metatranscriptomics) are urgently needed. Third, instead of purely observational studies, causal and functional ones should be strengthened. Although association analysis may provide important information for causeeffect deduction, correlation does not necessarily mean causation. Fourth, basic research targeting the microbiota-gut-brain axis in AD merits optimization; specifically, appropriate model systems are to be carefully selected. Host-specific interactions with microbiota, differences in environment and exposure, and the structural complexity of the brain should be taken into consideration. Finally, translation of basic research results into clinically relevant effects in humans should be expedited. The majority of data on the role of gut microbiota in AD are based on animal studies. Preclinical animal studies frequently end up with unexpected failures during clinical transition due to unidentified reasons. Alternatively, future therapeutic interventions will likely be based on individual gut microbiota composition due to significant differences in gut microbiota configurations and compositions among human populations.

Authors' Contributions KL and HLZ conceived the topic and designed the outline of this review; SL, JG, and MZ drafted the manuscript and contributed to the literature review and manuscript writing; SL prepared the figures; HLZ critically revised the manuscript.

Funding Information The work was supported by a grant from the National Natural Science Foundation of China (No. 81771299) to KL.

\section{Compliance with Ethical Standards}

Conflict of Interest The authors declare that they have no competing interests.

Declarations Zhang HL is affiliated with the National Natural Science Foundation of China. The views expressed are his own and do not necessarily represent the views of the National Natural Science Foundation of China or the Chinese government.

Open Access This article is licensed under a Creative Commons Attribution 4.0 International License, which permits use, sharing, adaptation, distribution and reproduction in any medium or format, as long as you give appropriate credit to the original author(s) and the source, provide a link to the Creative Commons licence, and indicate if changes were made. The images or other third party material in this article are included in the article's Creative Commons licence, unless indicated otherwise in a credit line to the material. If material is not included in the article's Creative Commons licence and your intended use is not permitted by statutory regulation or exceeds the permitted use, you will need to obtain permission directly from the copyright holder. To view a copy of this licence, visit http://creativecommons.org/licenses/by/4.0/. 


\section{References}

1. Long JM, Holtzman DM (2019) Alzheimer disease: an update on pathobiology and treatment strategies. Cell 179:312-339. https:// doi.org/10.1016/j.cell.2019.09.001

2. Hodson R (2018) Alzheimer's disease. Nature 559:S1. https://doi. org/10.1038/d41586-018-05717-6

3. Hardy JA, Higgins GA (1992) Alzheimer's disease: the amyloid cascade hypothesis. Science 256:184-185. https://doi.org/10. 1126/science. 1566067

4. Selkoe DJ, Hardy J (2016) The amyloid hypothesis of Alzheimer's disease at 25 years. EMBO Mol med 8:595-608. https://doi.org/10.15252/emmm.201606210

5. De Strooper B, Karran E (2016) The cellular phase of Alzheimer's disease. Cell 164:603-615. https://doi.org/10.1016/j.cell.2015.12. 056

6. Tapia-Rojas C, Cabezas-Opazo F, Deaton CA, Vergara EH, GVW J, Quintanilla RA (2019) It's all about tau. Prog Neurobiol 175: 54-76. https://doi.org/10.1016/j.pneurobio.2018.12.005

7. Panza F, Lozupone M, Logroscino G, Imbimbo BP (2019) A critical appraisal of amyloid- $\beta$-targeting therapies for Alzheimer disease. Nat Rev Neurol 15:73-88. https://doi.org/10.1038/ s41582-018-0116-6

8. Heneka MT, Carson MJ, El Khoury J et al (2015) Neuroinflammation in Alzheimer's disease. Lancet Neurol 14: 388-405. https://doi.org/10.1016/s1474-4422(15)70016-5

9. Ashraf GM, Tarasov VV, Makhmutova A, Chubarev VN, AvilaRodriguez M, Bachurin SO, Aliev G (2019) The possibility of an infectious etiology of Alzheimer disease. Mol Neurobiol 56: 4479-4491. https://doi.org/10.1007/s12035-018-1388-y

10. Becker RE, Kapogiannis D, Greig NH (2018) Does traumatic brain injury hold the key to the Alzheimer's disease puzzle? Alzheimers Dement 14:431-443. https://doi.org/10.1016/j.jalz. 2017.11.007

11. Guerreiro R, Wojtas A, Bras J, Carrasquillo M, Rogaeva E, Majounie E, Cruchaga C, Sassi C et al (2013) TREM2 variants in Alzheimer's disease. N Engl J Med 368:117-127. https://doi. org/10.1056/NEJMoa1211851

12. Naj AC, Jun G, Beecham GW, Wang LS, Vardarajan BN, Buros J, Gallins PJ, Buxbaum JD et al (2011) Common variants at MS4A4/MS4A6E, CD2AP, CD33 and EPHA1 are associated with late-onset Alzheimer's disease. Nat Genet 43:436-441. https://doi.org/10.1038/ng.801

13. Swerdlow RH (2018) Mitochondria and mitochondrial cascades in Alzheimer's disease. J Alzheimers Dis 62:1403-1416. https:// doi.org/10.3233/jad-170585

14. Nguyen TT, Ta QTH, Nguyen TTD, Le TT, Vo VG (2020) Role of Insulin Resistance in the Alzheimer's Disease Progression. Neurochem Res 45(7):1481-1491

15. Zhao Y, Gong CX (2015) From chronic cerebral hypoperfusion to alzheimer-like brain pathology and neurodegeneration. Cell Mol Neurobiol 35(1):101-110

16. Cryan JF, O'Riordan KJ, Cowan CSM, Sandhu KV, Bastiaanssen TFS, Boehme M, Codagnone MG, Cussotto S, Fulling C, Golubeva AV, Guzzetta KE, Jaggar M, Long- Smith CM, Lyte JM, Martin JA, Molinero-Perez A, Moloney G, Morelli E, Morillas E, O'Connor R, Cruz-Pereira JS, Peterson VL, Rea K, Ritz NL, Sherwin E, Spichak S, Teichman EM, Wouw MVD, Ventura-Silva AP, Wallace-Fitzsimons SE, Hyland N, Clarke G, Dinan TG (2019) The microbiota-gut-brain axis. Physiol Rev 99(4):1877-2013

17. Long-Smith C, O'Riordan KJ, Clarke G, Stanton C, Dinan TG, Cryan JF (2020) Microbiota-gut-brain axis: New therapeutic opportunities. Annu Rev Pharmacol Toxicol 60(1):477-502
18. Knight R, Vrbanac A, Taylor BC, Aksenov A, Callewaert C, Debelius J, Gonzalez A, Kosciolek T, McCall L, McDonald D, Melnik AV, Morton JT, Navas J, Quinn RA, Sanders JG, Swafford AD, Thompson LR, Tripathi A, Xu ZZ, Zaneveld JR, Zhu Caporaso QJG, Dorrestein PC (2018) Best practices for analysing microbiomes. Nat. Rev. Microbiol 16(7):410-422

19. Kim MS, Kim Y, Choi H, Kim W, Park S, Lee D, Kim DK, Kim HJ et al (2020) Transfer of a healthy microbiota reduces amyloid and tau pathology in an Alzheimer's disease animal model. Gut 69:283-294. https://doi.org/10.1136/gutjnl-2018-317431

20. Sonnenburg JL, Sonnenburg ED (2019) Vulnerability of the industrialized microbiota. Science 366. https://doi.org/10.1126/ science.aaw9255

21. Qin J, Li R, Raes J et al (2010) A human gut microbial gene catalogue established by metagenomic sequencing. Nature 464 : 59-65. https://doi.org/10.1038/nature08821

22. Gill SR, Pop M, Deboy RT et al (2006) Metagenomic analysis of the human distal gut microbiome. Science 312:1355-1359. https://doi.org/10.1126/science.1124234

23. Eckburg PB, Bik EM, Bernstein CN, Purdom E, Dethlefsen L, Sargent M, Gill SR, Nelson KE et al (2005) Diversity of the human intestinal microbial flora. Science 308:1635-1638. https://doi.org/10.1126/science.1110591

24. Perez-Muñoz ME, Arrieta MC, Ramer-Tait AE, Walter J (2017) A critical assessment of the "sterile womb" and "in utero colonization" hypotheses: implications for research on the pioneer infant microbiome. Microbiome 5:48. https://doi.org/10.1186/s40168017-0268-4

25. Dominguez-Bello MG, Costello EK, Contreras M, Magris M, Hidalgo G, Fierer N, Knight R (2010) Delivery mode shapes the acquisition and structure of the initial microbiota across multiple body habitats in newborns. Proc Natl Acad Sci U S A 107:1197111975. https://doi.org/10.1073/pnas.1002601107

26. Falony G, Joossens M, Vieira-Silva S, Wang J, Darzi Y, Faust K, Kurilshikov A, Bonder MJ et al (2016) Population-level analysis of gut microbiome variation. Science 352:560-564. https://doi. org/10.1126/science.aad3503

27. Schmidt TSB, Raes J, Bork P (2018) The human gut microbiome: from association to modulation. Cell 172:1198-1215. https://doi. org/10.1016/j.cell.2018.02.044

28. Claesson MJ, Cusack S, O'Sullivan O, Greene-Diniz R, de Weerd H, Flannery E, Marchesi JR, Falush D et al (2011) Composition, variability, and temporal stability of the intestinal microbiota of the elderly. Proc Natl Acad Sci U S A 108(Suppl 1):4586-4591. https://doi.org/10.1073/pnas.1000097107

29. Valdes AM, Walter J, Segal E, Spector TD (2018) Role of the gut microbiota in nutrition and health. BMJ 361:k2179. https://doi. org/10.1136/bmj.k2179

30. Schirmer M, Garner A, Vlamakis H, Xavier RJ (2019) Microbial genes and pathways in inflammatory bowel disease. Nat Rev Microbiol 17:497-511. https://doi.org/10.1038/s41579-019-0213-6

31. Durack J, Kimes NE, Lin DL, Rauch M, McKean M, McCauley K, Panzer AR, Mar JS et al (2018) Delayed gut microbiota development in high-risk for asthma infants is temporarily modifiable by Lactobacillus supplementation. Nat Commun 9:707. https:// doi.org/10.1038/s41467-018-03157-4

32. Tang WHW, Bäckhed F, Landmesser U, Hazen SL (2019) Intestinal microbiota in cardiovascular health and disease: JACC state-of-the-art review. J Am Coll Cardiol 73:2089-2105. https:// doi.org/10.1016/j.jacc.2019.03.024

33. Zhao L, Zhang F, Ding X, Wu G, Lam YY, Wang X, Fu H, Xue X et al (2018) Gut bacteria selectively promoted by dietary fibers alleviate type 2 diabetes. Science 359:1151-1156. https://doi.org/ 10.1126/science.aao5774

34. Wang X, Yang S, Li S, Zhao L, Hao Y, Qin J, Zhang L, Zhang C et al (2020) Aberrant gut microbiota alters host metabolome and 
impacts renal failure in humans and rodents. Gut:gutjnl-2019319766. https://doi.org/10.1136/gutjnl-2019-319766

35. Ticinesi A, Nouvenne A, Cerundolo N et al (2019) Gut microbiota, muscle mass and function in aging: a focus on physical frailty and sarcopenia. Nutrients 11. https://doi.org/10.3390/nu11071633

36. Nicholson JK, Holmes E, Kinross J, Burcelin R, Gibson G, Jia W, Pettersson S (2012) Host-gut microbiota metabolic interactions. Science 336:1262-1267. https://doi.org/10.1126/science.1223813

37. Barrett E, Ross RP, O'Toole PW, Fitzgerald GF, Stanton C (2012) $\gamma$-Aminobutyric acid production by culturable bacteria from the human intestine. J Appl Microbiol 113:411-417. https://doi.org/ 10.1111/j.1365-2672.2012.05344.x

38. Holzer P, Farzi A (2014) Neuropeptides and the microbiota-gutbrain axis. Adv Exp Med Biol 817:195-219. https://doi.org/10. 1007/978-1-4939-0897-4 9

39. Kawashima K, Misawa H, Moriwaki Y, Fujii YX, Fujii T, Horiuchi Y, Yamada T, Imanaka T et al (2007) Ubiquitous expression of acetylcholine and its biological functions in life forms without nervous systems. Life Sci 80:2206-2209. https://doi.org/ 10.1016/j.lfs.2007.01.059

40. Russell WR, Hoyles L, Flint HJ, Dumas ME (2013) Colonic bacterial metabolites and human health. Curr Opin Microbiol 16:246254. https://doi.org/10.1016/j.mib.2013.07.002

41. Landete JM, De las Rivas B, Marcobal A, Muñoz R (2008) Updated molecular knowledge about histamine biosynthesis by bacteria. Crit Rev Food Sci Nutr 48:697-714. https://doi.org/10. 1080/10408390701639041

42. Thomas CM, Hong T, van Pijkeren JP, Hemarajata P, Trinh DV, $\mathrm{Hu}$ W, Britton RA, Kalkum M et al (2012) Histamine derived from probiotic Lactobacillus reuteri suppresses TNF via modulation of PKA and ERK signaling. PLoS One 7:e31951. https://doi. org/10.1371/journal.pone.0031951

43. Clarke G, Stilling RM, Kennedy PJ, Stanton C, Cryan JF, Dinan TG (2014) Minireview: Gut microbiota: the neglected endocrine organ. Mol Endocrinol 28:1221-1238. https://doi.org/10.1210/ me.2014-1108

44. Dinan TG, Cryan JF (2017) Gut instincts: microbiota as a key regulator of brain development, ageing and neurodegeneration. J Physiol 595:489-503. https://doi.org/10.1113/jp273106

45. Dalile B, Van Oudenhove L, Vervliet B, Verbeke K (2019) The role of short-chain fatty acids in microbiota-gut-brain communication. Nat Rev Gastroenterol Hepatol 16:461-478. https://doi. org/10.1038/s41575-019-0157-3

46. Samuel BS, Shaito A, Motoike T, Rey FE, Backhed F, Manchester JK, Hammer RE, Williams SC et al (2008) Effects of the gut microbiota on host adiposity are modulated by the short-chain fatty-acid binding $\mathrm{G}$ protein-coupled receptor, Gpr41. Proc Natl Acad Sci U S A 105:16767-16772. https:// doi.org/10.1073/pnas.0808567105

47. Soliman ML, Rosenberger TA (2011) Acetate supplementation increases brain histone acetylation and inhibits histone deacetylase activity and expression. Mol Cell Biochem 352:173-180. https:// doi.org/10.1007/s11010-011-0751-3

48. Heck AL, Handa RJ (2019) Sex differences in the hypothalamicpituitary-adrenal axis response to stress: an important role for gonadal hormones. Neuropsychopharmacology 44:45-58. https:// doi.org/10.1038/s41386-018-0167-9

49. Crumeyrolle-Arias M, Jaglin M, Bruneau A, Vancassel S, Cardona A, Daugé V, Naudon L, Rabot S (2014) Absence of the gut microbiota enhances anxiety-like behavior and neuroendocrine response to acute stress in rats. Psychoneuroendocrinology 42:207-217. https://doi.org/10.1016/ j.psyneuen.2014.01.014

50. Sudo N, Chida Y, Aiba Y, Sonoda J, Oyama N, Yu XN, Kubo C, Koga Y (2004) Postnatal microbial colonization programs the hypothalamic-pituitary-adrenal system for stress response in mice.
J Physiol 558:263-275. https://doi.org/10.1113/jphysiol.2004. 063388

51. Neufeld KM, Kang N, Bienenstock J, Foster JA (2011) Reduced anxiety-like behavior and central neurochemical change in germfree mice. Neurogastroenterol Motil 23(255-264):e119. https:// doi.org/10.1111/j.1365-2982.2010.01620.x

52. Spielman LJ, Gibson DL, Klegeris A (2018) Unhealthy gut, unhealthy brain: the role of the intestinal microbiota in neurodegenerative diseases. Neurochem Int 120:149-163. https://doi.org/10. 1016/j.neuint.2018.08.005

53. Fülling C, Dinan TG, Cryan JF (2019) Gut microbe to brain signaling: what happens in vagus.... Neuron 101:998-1002. https:// doi.org/10.1016/j.neuron.2019.02.008

54. Bonaz B, Bazin T, Pellissier S (2018) The vagus nerve at the interface of the microbiota-gut-brain axis. Front Neurosci 12:49. https://doi.org/10.3389/fnins.2018.00049

55. Osadchiy V, Martin CR, Mayer EA (2019) Gut microbiome and modulation of CNS function. Compr Physiol 10:57-72. https:// doi.org/10.1002/cphy.c180031

56. Kaelberer MM, Buchanan KL, Klein ME et al (2018) A gut-brain neural circuit for nutrient sensory transduction. Science 361 . https://doi.org/10.1126/science.aat5236

57. Bravo JA, Forsythe P, Chew MV, Escaravage E, Savignac HM, Dinan TG, Bienenstock J, Cryan JF (2011) Ingestion of Lactobacillus strain regulates emotional behavior and central GABA receptor expression in a mouse via the vagus nerve. Proc Natl Acad Sci U S A 108:16050-16055. https://doi.org/10.1073/ pnas. 1102999108

58. O'Leary OF, Ogbonnaya ES, Felice D et al (2018) The vagus nerve modulates BDNF expression and neurogenesis in the hippocampus. Eur Neuropsychopharmacol 28:307-316. https://doi. org/10.1016/j.euroneuro.2017.12.004

59. Hooper LV, Littman DR, Macpherson AJ (2012) Interactions between the microbiota and the immune system. Science 336:12681273. https://doi.org/10.1126/science. 1223490

60. Olszak T, An D, Zeissig S, Vera MP, Richter J, Franke A, Glickman JN, Siebert R et al (2012) Microbial exposure during early life has persistent effects on natural killer $\mathrm{T}$ cell function. Science 336:489-493. https://doi.org/10.1126/science.1219328

61. Erny D, Hrabě de Angelis AL, Jaitin D, Wieghofer P, Staszewski O, David E, Keren-Shaul H, Mahlakoiv T et al (2015) Host microbiota constantly control maturation and function of microglia in the CNS. Nat Neurosci 18:965-977. https://doi.org/10.1038/nn. 4030

62. Fung TC, Olson CA, Hsiao EY (2017) Interactions between the microbiota, immune and nervous systems in health and disease. Nat Neurosci 20:145-155. https://doi.org/10.1038/nn.4476

63. Cattaneo A, Cattane N, Galluzzi S, Provasi S, Lopizzo N, Festari C, Ferrari C, Guerra UP et al (2017) Association of brain amyloidosis with pro-inflammatory gut bacterial taxa and peripheral inflammation markers in cognitively impaired elderly. Neurobiol Aging 49:60-68. https://doi.org/10.1016/j.neurobiolaging.2016. 08.019

64. Zhuang ZQ, Shen LL, Li WW, Fu X, Zeng F, Gui L, Lü Y, Cai M et al (2018) Gut microbiota is altered in patients with Alzheimer's disease. J Alzheimers Dis 63:1337-1346. https://doi.org/10.3233/ jad-180176

65. Vogt NM, Kerby RL, Dill-McFarland KA et al (2017) Gut microbiome alterations in Alzheimer's disease. Sci Rep 7:13537. https://doi.org/10.1038/s41598-017-13601-y

66. Paley EL, Merkulova-Rainon T, Faynboym A, Shestopalov VI, Aksenoff I (2018) Geographical distribution and diversity of gut microbial NADH:ubiquinone oxidoreductase sequence associated with Alzheimer's disease. J Alzheimers Dis 61:1531-1540. https://doi.org/10.3233/jad-170764 
67. Emery DC, Shoemark DK, Batstone TE, Waterfall CM, Coghill JA, Cerajewska TL, Davies M, West NX et al (2017) 16S rRNA next generation sequencing analysis shows bacteria in Alzheimer's post-mortem brain. Front Aging Neurosci 9:195. https://doi.org/10.3389/fnagi.2017.00195

68. Zhang L, Wang Y, Xiayu X, Shi C, Chen W, Song N, Fu X, Zhou $\mathrm{R}$ et al (2017) Altered gut microbiota in a mouse model of Alzheimer's disease. J Alzheimers Dis 60:1241-1257. https:// doi.org/10.3233/jad-170020

69. Bäuerl C, Collado MC, Diaz Cuevas A, Viña J, Pérez Martínez G (2018) Shifts in gut microbiota composition in an APP/PSS1 transgenic mouse model of Alzheimer's disease during lifespan. Lett Appl Microbiol 66:464-471. https://doi.org/10.1111/lam. 12882

70. Shen L, Liu L, Ji HF (2017) Alzheimer's disease histological and behavioral manifestations in transgenic mice correlate with specific gut microbiome state. J Alzheimers Dis 56:385-390. https://doi. org/10.3233/jad-160884

71. Honarpisheh P, Reynolds CR, Blasco Conesa MP et al (2020) Dysregulated gut homeostasis observed prior to the accumulation of the brain amyloid- $\beta$ in Tg2576 mice. Int J Mol Sci 21. https:// doi.org/10.3390/ijms21051711

72. Jucker M, Walker LC (2018) Propagation and spread of pathogenic protein assemblies in neurodegenerative diseases. Nat Neurosci 21:1341-1349. https://doi.org/10.1038/s41593-0180238-6

73. Del Tredici K, Braak H (2016) Review: Sporadic Parkinson's disease: development and distribution of $\alpha$-synuclein pathology. Neuropathol Appl Neurobiol 42:33-50. https://doi.org/10.1111/ nan. 12298

74. Brandscheid C, Schuck F, Reinhardt S, Schäfer KH, Pietrzik CU, Grimm M, Hartmann T, Schwiertz A et al (2017) Altered gut microbiome composition and tryptic activity of the $5 \mathrm{xFAD}$ Alzheimer's mouse model. J Alzheimers Dis 56:775-788. https://doi.org/10.3233/jad-160926

75. Semar S, Klotz M, Letiembre M, van Ginneken C, Braun A, Jost V, Bischof M, Lammers WJ et al (2013) Changes of the enteric nervous system in amyloid- $\beta$ protein precursor transgenic mice correlate with disease progression. J Alzheimers Dis 36:7-20. https://doi.org/10.3233/jad-120511

76. Ho L, Ono K, Tsuji M, Mazzola P, Singh R, Pasinetti GM (2018) Protective roles of intestinal microbiota derived short chain fatty acids in Alzheimer's disease-type beta-amyloid neuropathological mechanisms. Expert Rev Neurother 18:83-90. https://doi.org/10. 1080/14737175.2018.1400909

77. Gao Q, Wang Y, Wang X et al (2019) Decreased levels of circulating trimethylamine $\mathrm{N}$-oxide alleviate cognitive and pathological deterioration in transgenic mice: a potential therapeutic approach for Alzheimer's disease. Aging (Albany NY) 11:8642-8663. https://doi.org/10.18632/aging.102352

78. Evin G, Li QX (2012) Platelets and Alzheimer's disease: potential of APP as a biomarker. World J Psychiatry 2:102-113. https://doi. org/10.5498/wjp.v2.i6.102

79. Zhu W, Gregory JC, Org E, Buffa JA, Gupta N, Wang Z, Li L, Fu $X$ et al (2016) Gut microbial metabolite TMAO enhances platelet hyperreactivity and thrombosis risk. Cell 165:111-124. https:// doi.org/10.1016/j.cell.2016.02.011

80. Colciaghi F, Marcello E, Borroni B, Zimmermann M, Caltagirone C, Cattabeni F, Padovani A, di Luca M (2004) Platelet APP, ADAM 10 and BACE alterations in the early stages of Alzheimer disease. Neurology 62:498-501. https://doi.org/10. 1212/01.wnl.0000106953.49802.9c

81. Kiriyama Y, Nochi H (2019) The biosynthesis, signaling, and neurological functions of bile acids. Biomolecules 9. https://doi. org/10.3390/biom9060232
82. Quinn M, McMillin M, Galindo C, Frampton G, Pae HY, DeMorrow S (2014) Bile acids permeabilize the blood brain barrier after bile duct ligation in rats via Rac1-dependent mechanisms. Dig Liver Dis 46:527-534. https://doi.org/10.1016/j.dld. 2014.01.159

83. Li T, Chiang JY (2015) Bile acids as metabolic regulators. Curr Opin Gastroenterol 31:159-165. https://doi.org/10.1097/mog. 0000000000000156

84. Gamba P, Testa G, Sottero B, Gargiulo S, Poli G, Leonarduzzi G (2012) The link between altered cholesterol metabolism and Alzheimer's disease. Ann N Y Acad Sci 1259:54-64. https://doi. org/10.1111/j.1749-6632.2012.06513.x

85. Jia W, Rajani C, Kaddurah-Daouk R, Li H (2019) Expert insights: the potential role of the gut microbiome-bile acid-brain axis in the development and progression of Alzheimer's disease and hepatic encephalopathy. Med Res Rev 40:1496-1507. https://doi.org/10. 1002/med.21653

86. Zhou Y, Smith D, Leong BJ, Brännström K, Almqvist F, Chapman MR (2012) Promiscuous cross-seeding between bacterial amyloids promotes interspecies biofilms. J Biol Chem 287: 35092-35103. https://doi.org/10.1074/jbc.M1 12.383737

87. Schwartz K, Boles BR (2013) Microbial amyloids-functions and interactions within the host. Curr Opin Microbiol 16:93-99. https://doi.org/10.1016/j.mib.2012.12.001

88. Du L, Zhang Y, Chen Y, Zhu J, Yang Y, Zhang HL (2017) Role of microglia in neurological disorders and their potentials as a therapeutic target. Mol Neurobiol 54:7567-7584. https://doi.org/10. 1007/s12035-016-0245-0

89. Hansen DV, Hanson JE, Sheng M (2018) Microglia in Alzheimer's disease. J Cell Biol 217:459-472. https://doi.org/ 10.1083/jcb.201709069

90. Condello C, Yuan P, Schain A, Grutzendler J (2015) Microglia constitute a barrier that prevents neurotoxic protofibrillar $A \beta 42$ hotspots around plaques. Nat Commun 6:6176. https://doi.org/ $10.1038 /$ ncomms 7176

91. Obermeier B, Daneman R, Ransohoff RM (2013) Development, maintenance and disruption of the blood-brain barrier. Nat Med 19:1584-1596. https://doi.org/10.1038/nm.3407

92. Zenaro E, Piacentino G, Constantin G (2017) The blood-brain barrier in Alzheimer's disease. Neurobiol Dis 107:41-56. https:// doi.org/10.1016/j.nbd.2016.07.007

93. Braniste V, Al-Asmakh M, Kowal C et al (2014) The gut microbiota influences blood-brain barrier permeability in mice. Sci Transl Med 6:263ra158. https://doi.org/10.1126/scitranslmed. 3009759

94. Sampson TR, Mazmanian SK (2015) Control of brain development, function, and behavior by the microbiome. Cell Host Microbe 17:565-576. https://doi.org/10.1016/j.chom.2015.04. 011

95. Hoyles L, Snelling T, Umlai UK, Nicholson JK, Carding SR, Glen RC, McArthur S (2018) Microbiome-host systems interactions: protective effects of propionate upon the blood-brain barrier. Microbiome 6:55. https://doi.org/10.1186/s40168-018-0439-y

96. Pellegrini C, Antonioli L, Colucci R, Blandizzi C, Fornai M (2018) Interplay among gut microbiota, intestinal mucosal barrier and enteric neuro-immune system: a common path to neurodegenerative diseases? Acta Neuropathol 136:345-361. https://doi.org/ 10.1007/s00401-018-1856-5

97. Itzhaki RF, Lathe R, Balin BJ, Ball MJ, Bearer EL, Braak H, Bullido MJ, Carter C et al (2016) Microbes and Alzheimer's disease. J Alzheimers Dis 51:979-984. https://doi.org/10.3233/jad160152

98. Friedland RP (2015) Mechanisms of molecular mimicry involving the microbiota in neurodegeneration. J Alzheimers Dis 45:349362. https://doi.org/10.3233/jad-142841 
99. Soscia SJ, Kirby JE, Washicosky KJ, Tucker SM, Ingelsson M, Hyman B, Burton MA, Goldstein LE et al (2010) The Alzheimer's disease-associated amyloid beta-protein is an antimicrobial peptide. PLoS One 5:e9505. https://doi.org/10.1371/journal.pone. 0009505

100. Kumar DK, Choi SH, Washicosky KJ et al (2016) Amyloid- $\beta$ peptide protects against microbial infection in mouse and worm models of Alzheimer's disease. Sci Transl Med 8:340ra372. https://doi.org/10.1126/scitranslmed.aaf1059

101. Eimer WA, Vijaya Kumar DK, Navalpur Shanmugam NK et al (2018) Alzheimer's disease-associated $\beta$-amyloid is rapidly seeded by Herpesviridae to protect against brain infection. Neuron 99: 56-63.e53. https://doi.org/10.1016/j.neuron.2018.06.030

102. Lukiw WJ (2016) Bacteroides fragilis lipopolysaccharide and inflammatory signaling in Alzheimer's disease. Front Microbiol 7: 1544. https://doi.org/10.3389/fmicb.2016.01544

103. Liu CY, Wang X, Liu C, Zhang HL (2019) Pharmacological targeting of microglial activation: new therapeutic approach. Front Cell Neurosci 13:514. https://doi.org/10.3389/fncel.2019. 00514

104. Zhao Y, Jaber V, Lukiw WJ (2017) Secretory products of the human GI tract microbiome and their potential impact on Alzheimer's disease (AD): detection of lipopolysaccharide (LPS) in AD hippocampus. Front Cell Infect Microbiol 7:318. https:// doi.org/10.3389/fcimb.2017.00318

105. Rolls A, Shechter R, London A, Ziv Y, Ronen A, Levy R, Schwartz M (2007) Toll-like receptors modulate adult hippocampal neurogenesis. Nat Cell Biol 9:1081-1088. https://doi.org/10. $1038 /$ ncb 1629

106. Alexandrov P, Zhai Y, Li W, Lukiw W (2019) Lipopolysaccharide-stimulated, NF-kB-, miRNA-146a- and miRNA-155-mediated molecular-genetic communication between the human gastrointestinal tract microbiome and the brain. Folia Neuropathol 57:211-219. https://doi.org/10.5114/fn.2019. 88449

107. Hayward JA, Mathur A, Ngo C, Man SM (2018) Cytosolic recognition of microbes and pathogens: inflammasomes in action. Microbiol Mol Biol Rev 82. https://doi.org/10.1128/mmbr.00015-18

108. Halle A, Hornung V, Petzold GC, Stewart CR, Monks BG, Reinheckel T, Fitzgerald KA, Latz E et al (2008) The NALP3 inflammasome is involved in the innate immune response to amyloid-beta. Nat Immunol 9:857-865. https://doi.org/10.1038/ni. 1636

109. Arioz BI, Tastan B, Tarakcioglu E, Tufekci KU, Olcum M, Ersoy N, Bagriyanik A, Genc K et al (2019) Melatonin attenuates LPSinduced acute depressive-like behaviors and microglial NLRP3 Inflammasome activation through the SIRT1/Nrf2 pathway. Front Immunol 10:1511. https://doi.org/10.3389/fimmu.2019. 01511

110. Holmes C, Cunningham C, Zotova E, Culliford D, Perry VH (2011) Proinflammatory cytokines, sickness behavior, and Alzheimer disease. Neurology 77:212-218. https://doi.org/10. 1212/WNL.0b013e318225ae07

111. Holmes C, Cunningham C, Zotova E, Woolford J, Dean C, Kerr S, Culliford D, Perry VH (2009) Systemic inflammation and disease progression in Alzheimer disease. Neurology 73:768-774. https:// doi.org/10.1212/WNL.0b013e3181b6bb95

112. Sochocka M, Donskow-Łysoniewska K, Diniz BS, Kurpas D, Brzozowska E, Leszek J (2019) The gut microbiome alterations and inflammation-driven pathogenesis of Alzheimer's disease-a critical review. Mol Neurobiol 56:1841-1851. https://doi.org/10. 1007/s12035-018-1188-4

113. Maynard CL, Elson CO, Hatton RD, Weaver CT (2012) Reciprocal interactions of the intestinal microbiota and immune system. Nature 489:231-241. https://doi.org/10.1038/ nature 11551
114. Wang X, Sun G, Feng T, Zhang J, Huang X, Wang T, Xie Z, Chu $X$ et al (2019) Sodium oligomannate therapeutically remodels gut microbiota and suppresses gut bacterial amino acids-shaped neuroinflammation to inhibit Alzheimer's disease progression. Cell Res 29:787-803. https://doi.org/10.1038/s41422-019-0216-x

115. Treangen TJ, Wagner J, Burns MP, Villapol S (2018) Traumatic brain injury in mice induces acute bacterial dysbiosis within the fecal microbiome. Front Immunol 9:2757. https://doi.org/10. 3389/fimmu.2018.02757

116. Sundman MH, Chen NK, Subbian V, Chou YH (2017) The bidirectional gut-brain-microbiota axis as a potential nexus between traumatic brain injury, inflammation, and disease. Brain Behav Immun 66:31-44. https://doi.org/10.1016/j.bbi.2017.05.009

117. Catania C, Sotiropoulos I, Silva R, Onofri C, Breen KC, Sousa N, Almeida OFX (2009) The amyloidogenic potential and behavioral correlates of stress. Mol Psychiatry 14:95-105. https://doi.org/10. 1038/sj.mp.4002101

118. Niraula A, Sheridan JF, Godbout JP (2017) Microglia priming with aging and stress. Neuropsychopharmacology 42:318-333. https://doi.org/10.1038/npp.2016.185

119. Cryan JF, Dinan TG (2012) Mind-altering microorganisms: the impact of the gut microbiota on brain and behaviour. Nat Rev Neurosci 13:701-712. https://doi.org/10.1038/nrn3346

120. Protter DSW, Parker R (2016) Principles and properties of stress granules. Trends Cell Biol 26:668-679. https://doi.org/10.1016/j. tcb.2016.05.004

121. Wolozin B, Ivanov P (2019) Stress granules and neurodegeneration. Nat Rev Neurosci 20:649-666. https://doi.org/10.1038/ s41583-019-0222-5

122. Dobra I, Pankivskyi S, Samsonova A, Pastre D, Hamon L (2018) Relation between stress granules and cytoplasmic protein aggregates linked to neurodegenerative diseases. Curr Neurol Neurosci Rep 18:107. https://doi.org/10.1007/s11910-018-0914-7

123. Vanderweyde T, Apicco DJ, Youmans-Kidder K, Ash PEA, Cook C, Lummertz da Rocha E, Jansen-West K, Frame AA et al (2016) Interaction of tau with the RNA-binding protein TIA1 regulates tau pathophysiology and toxicity. Cell Rep 15:1455-1466. https:// doi.org/10.1016/j.celrep.2016.04.045

124. Ambadipudi S, Biernat J, Riedel D, Mandelkow E, Zweckstetter M (2017) Liquid-liquid phase separation of the microtubulebinding repeats of the Alzheimer-related protein tau. Nat Commun 8:275. https://doi.org/10.1038/s41467-017-00480-0

125. Luo J, Mills K, le Cessie S, Noordam R, van Heemst D (2020) Ageing, age-related diseases and oxidative stress: what to do next? Ageing Res Rev 57:100982. https://doi.org/10.1016/j.arr.2019. 100982

126. Basu M, Courtney SC, Brinton MA (2017) Arsenite-induced stress granule formation is inhibited by elevated levels of reduced glutathione in West Nile virus-infected cells. PLoS Pathog 13: e1006240. https://doi.org/10.1371/journal.ppat.1006240

127. Dumitrescu L, Popescu-Olaru I, Cozma L, Tulbă D, Hinescu ME, Ceafalan LC, Gherghiceanu M, Popescu BO (2018) Oxidative stress and the microbiota-gut-brain axis. Oxidative Med Cell Longev 2018:2406594-2406512. https://doi.org/10.1155/2018/ 2406594

128. Kumar A, Wu H, Collier-Hyams LS, Hansen JM, Li T, Yamoah K, Pan ZQ, Jones DP et al (2007) Commensal bacteria modulate cullin-dependent signaling via generation of reactive oxygen species. EMBO J 26:4457-4466. https://doi.org/10.1038/sj.emboj. 7601867

129. Wang A, Keita $\AA$ V, Phan V, McKay CM, Schoultz I, Lee J, Murphy MP, Fernando M et al (2014) Targeting mitochondriaderived reactive oxygen species to reduce epithelial barrier dysfunction and colitis. Am J Pathol 184:2516-2527. https://doi.org/ 10.1016/j.ajpath.2014.05.019 
130. Reese AT, Cho EH, Klitzman B et al (2018) Antibiotic-induced changes in the microbiota disrupt redox dynamics in the gut. Elife 7. https://doi.org/10.7554/eLife.35987

131. Cobley JN, Fiorello ML, Bailey DM (2018) 13 reasons why the brain is susceptible to oxidative stress. Redox Biol 15:490-503. https://doi.org/10.1016/j.redox.2018.01.008

132. Mottawea W, Chiang CK, Mühlbauer M, Starr AE, Butcher J, Abujamel T, Deeke SA, Brandel A et al (2016) Altered intestinal microbiota-host mitochondria crosstalk in new onset Crohn's disease. Nat Commun 7:13419. https://doi.org/10.1038/ ncomms 13419

133. Ostojic SM (2018) Inadequate production of H(2) by gut microbiota and Parkinson disease. Trends Endocrinol Metab 29:286288. https://doi.org/10.1016/j.tem.2018.02.006

134. Baglietto-Vargas D, Shi J, Yaeger DM, Ager R, LaFerla FM (2016) Diabetes and Alzheimer's disease crosstalk. Neurosci Biobehav Rev 64:272-287. https://doi.org/10.1016/j.neubiorev. 2016.03.005

135. Boccardi V, Murasecco I, Mecocci P (2019) Diabetes drugs in the fight against Alzheimer's disease. Ageing Res Rev 54:100936. https://doi.org/10.1016/j.arr.2019.100936

136. Steen E, Terry BM, Rivera EJ et al (2005) Impaired insulin and insulin-like growth factor expression and signaling mechanisms in Alzheimer's disease-is this type 3 diabetes? J Alzheimers Dis 7: 63-80. https://doi.org/10.3233/jad-2005-7107

137. Luchsinger JA, Tang MX, Shea S, Mayeux R (2004) Hyperinsulinemia and risk of Alzheimer disease. Neurology 63: 1187-1192. https://doi.org/10.1212/01.wnl.0000140292.04932.87

138. Turnbaugh PJ, Ley RE, Mahowald MA, Magrini V, Mardis ER, Gordon JI (2006) An obesity-associated gut microbiome with increased capacity for energy harvest. Nature 444:1027-1031. https://doi.org/10.1038/nature05414

139. Zarrinpar A, Chaix A, Xu ZZ, Chang MW, Marotz CA, Saghatelian A, Knight R, Panda S (2018) Antibiotic-induced microbiome depletion alters metabolic homeostasis by affecting gut signaling and colonic metabolism. Nat Commun 9:2872. https://doi.org/10.1038/s41467-018-05336-9

140. Bagarolli RA, Tobar N, Oliveira AG, Araújo TG, Carvalho BM, Rocha GZ, Vecina JF, Calisto K et al (2017) Probiotics modulate gut microbiota and improve insulin sensitivity in DIO mice. J Nutr Biochem 50:16-25. https://doi.org/10.1016/j.jnutbio.2017.08.006

141. Soto M, Herzog C, Pacheco JA, Fujisaka S, Bullock K, Clish CB, Kahn CR (2018) Gut microbiota modulate neurobehavior through changes in brain insulin sensitivity and metabolism. Mol Psychiatry 23:2287-2301. https://doi.org/10.1038/s41380-0180086-5

142. Bonfili L, Cecarini V, Gogoi O, Berardi S, Scarpona S, Angeletti M, Rossi G, Eleuteri AM (2020) Gut microbiota manipulation through probiotics oral administration restores glucose homeostasis in a mouse model of Alzheimer's disease. Neurobiol Aging 87: 35-43. https://doi.org/10.1016/j.neurobiolaging.2019.11.004

143. Claesson MJ, Jeffery IB, Conde S, Power SE, O'Connor EM, Cusack S, Harris HMB, Coakley M et al (2012) Gut microbiota composition correlates with diet and health in the elderly. Nature 488:178-184. https://doi.org/10.1038/nature11319

144. Berti V, Walters M, Sterling J, Quinn CG, Logue M, Andrews R, Matthews DC, Osorio RS et al (2018) Mediterranean diet and 3year Alzheimer brain biomarker changes in middle-aged adults. Neurology 90:e1789-e1798. https://doi.org/10.1212/wnl. 0000000000005527

145. Del Chierico F, Vernocchi P, Dallapiccola B, Putignani L (2014) Mediterranean diet and health: food effects on gut microbiota and disease control. Int J Mol Sci 15:11678-11699. https://doi.org/10. 3390/ijms 150711678

146. De Filippis F, Pellegrini N, Vannini L et al (2016) High-level adherence to a Mediterranean diet beneficially impacts the gut microbiota and associated metabolome. Gut 65:1812-1821. https://doi.org/10.1136/gutjnl-2015-309957

147. Shi H, Wang Q, Zheng M, Hao S, Lum JS, Chen X, Huang XF, $\mathrm{Yu}$ Y et al (2020) Supplement of microbiota-accessible carbohydrates prevents neuroinflammation and cognitive decline by improving the gut microbiota-brain axis in diet-induced obese mice. J Neuroinflammation 17:77. https://doi.org/10.1186/s12974-02001760-1

148. Cummings J, Feldman HH, Scheltens P (2019) The "rights" of precision drug development for Alzheimer's disease. Alzheimers Res Ther 11:76. https://doi.org/10.1186/s13195-019-0529-5

149. Mittal R, Debs LH, Patel AP, Nguyen D, Patel K, O'Connor G, Grati M', Mittal J et al (2017) Neurotransmitters: the critical modulators regulating gut-brain axis. J Cell Physiol 232:2359-2372. https://doi.org/10.1002/jcp. 25518

150. Anand R, Gill KD, Mahdi AA (2014) Therapeutics of Alzheimer's disease: past, present and future. Neuropharmacology 76(Pt a):27-50. https://doi.org/10.1016/j. neuropharm.2013.07.004

151. Kandimalla R, Reddy PH (2017) Therapeutics of neurotransmitters in Alzheimer's disease. J Alzheimers Dis 57:1049-1069. https://doi.org/10.3233/jad-161118

152. Zlomuzica A, Dere D, Binder S, De Souza Silva MA, Huston JP, Dere E (2016) Neuronal histamine and cognitive symptoms in Alzheimer's disease. Neuropharmacology 106:135-145. https:// doi.org/10.1016/j.neuropharm.2015.05.007

153. Gibson GR, Hutkins R, Sanders ME, Prescott SL, Reimer RA, Salminen SJ, Scott K, Stanton C et al (2017) Expert consensus document: The International Scientific Association for Probiotics and Prebiotics (ISAPP) consensus statement on the definition and scope of prebiotics. Nat Rev Gastroenterol Hepatol 14:491-502. https://doi.org/10.1038/nrgastro.2017.75

154. Suez J, Zmora N, Segal E, Elinav E (2019) The pros, cons, and many unknowns of probiotics. Nat Med 25:716-729. https://doi. org/10.1038/s41591-019-0439-x

155. Abraham D, Feher J, Scuderi GL, Szabo D, Dobolyi A, Cservenak M, Juhasz J, Ligeti B et al (2019) Exercise and probiotics attenuate the development of Alzheimer's disease in transgenic mice: role of microbiome. Exp Gerontol 115:122-131. https://doi.org/10.1016/ j.exger.2018.12.005

156. Rezaei Asl Z, Sepehri G, Salami M (2019) Probiotic treatment improves the impaired spatial cognitive performance and restores synaptic plasticity in an animal model of Alzheimer's disease. Behav Brain Res 376:112183. https://doi.org/10.1016/j.bbr.2019. 112183

157. Yang X, Yu D, Xue L, Li H, Du J (2020) Probiotics modulate the microbiota-gut-brain axis and improve memory deficits in aged SAMP8 mice. Acta Pharm Sin B 10:475-487. https://doi.org/10. 1016/j.apsb.2019.07.001

158. Leblhuber F, Egger M, Schuetz B, Fuchs D (2018) Commentary: Effect of probiotic supplementation on cognitive function and metabolic status in Alzheimer's disease: a randomized, doubleblind and controlled trial. Front Aging Neurosci 10:54. https:// doi.org/10.3389/fnagi.2018.00054

159. McNulty NP, Yatsunenko T, Hsiao A et al (2011) The impact of a consortium of fermented milk strains on the gut microbiome of gnotobiotic mice and monozygotic twins. Sci Transl Med 3: 106ra106. https://doi.org/10.1126/scitranslmed.3002701

160. Sotoudegan F, Daniali M, Hassani S, Nikfar S, Abdollahi M (2019) Reappraisal of probiotics safety in human. Food Chem Toxicol 129:22-29. https://doi.org/10.1016/j.fct.2019.04.032

161. Slavin J (2013) Fiber and prebiotics: mechanisms and health benefits. Nutrients 5:1417-1435. https://doi.org/10.3390/nu5041417

162. DeMartino P, Cockburn DW (2020) Resistant starch: impact on the gut microbiome and health. Curr Opin Biotechnol 61:66-71. https://doi.org/10.1016/j.copbio.2019.10.008 
163. Bendiks ZA, Knudsen KEB, Keenan MJ, Marco ML (2020) Conserved and variable responses of the gut microbiome to resistant starch type 2. Nutr Res 77:12-28. https://doi.org/10.1016/j. nutres.2020.02.009

164. Míguez B, Gómez B, Parajó JC, Alonso JL (2018) Potential of Fructooligosaccharides and xylooligosaccharides as substrates to counteract the undesirable effects of several antibiotics on elder fecal microbiota: a first in vitro approach. J Agric Food Chem 66: 9426-9437. https://doi.org/10.1021/acs.jafc.8b02940

165. Schokker D, Fledderus J, Jansen R, Vastenhouw SA, de Bree FM, Smits MA, Jansman AAJM (2018) Supplementation of fructooligosaccharides to suckling piglets affects intestinal microbiota colonization and immune development. J Anim Sci 96:2139-2153. https://doi.org/10.1093/jas/sky110

166. Chen D, Yang X, Yang J, Lai G, Yong T, Tang X, Shuai O, Zhou $G$ et al (2017) Prebiotic effect of fructooligosaccharides from Morinda officinalis on Alzheimer's disease in rodent models by targeting the microbiota-gut-brain axis. Front Aging Neurosci 9: 403. https://doi.org/10.3389/fnagi.2017.00403

167. Sun J, Liu S, Ling Z, Wang F, Ling Y, Gong T, Fang N, Ye S et al (2019) Fructooligosaccharides ameliorating cognitive deficits and neurodegeneration in APP/PS1 transgenic mice through modulating gut microbiota. J Agric Food Chem 67:3006-3017. https://doi. org/10.1021/acs.jafc.8b07313

168. Shokryazdan P, Faseleh Jahromi M, Navidshad B, Liang JB (2017) Effects of prebiotics on immune system and cytokine expression. Med Microbiol Immunol 206:1-9. https://doi.org/10. 1007/s00430-016-0481-y

169. Allegretti JR, Kassam Z, Osman M, Budree S, Fischer M, Kelly CR (2018) The 5D framework: a clinical primer for fecal microbiota transplantation to treat Clostridium difficile infection. Gastrointest Endosc 87:18-29. https://doi.org/10.1016/j.gie. 2017.05.036

170. Allegretti JR, Mullish BH, Kelly C, Fischer M (2019) The evolution of the use of faecal microbiota transplantation and emerging therapeutic indications. Lancet 394:420-431. https://doi.org/10. 1016/s0140-6736(19)31266-8

171. Sun J, Xu J, Ling Y, Wang F, Gong T, Yang C, Ye S, Ye K et al (2019) Fecal microbiota transplantation alleviated Alzheimer's disease-like pathogenesis in APP/PS1 transgenic mice. Transl Psychiatry 9:189. https://doi.org/10.1038/s41398-019-0525-3

172. Mullish BH, Quraishi MN, Segal JP, McCune VL, Baxter M, Marsden GL, Moore DJ, Colville A et al (2018) The use of faecal microbiota transplant as treatment for recurrent or refractory Clostridium difficile infection and other potential indications: Joint British Society of Gastroenterology (BSG) and Healthcare Infection Society (HIS) guidelines. Gut 67:1920-1941. https://doi. org/10.1136/gutjnl-2018-316818

Publisher's Note Springer Nature remains neutral with regard to jurisdictional claims in published maps and institutional affiliations. 